\title{
LOS ANNALES MARTYRUM \\ TRANSMITIDOS POR MADRID, BN, 10029 Y MADRID, BRAH, 78: EDICIÓN, ESTUDIO Y PANORÁMICA DE SU INFLUENCIA EN LA LITERATURA ANALÍSTICA LATINA DE LA HISPANIA MEDIEVAL
}

\author{
THE ANNALES MARTYRUM TRANSMITTED IN MADRID, BN, 10029 AND \\ MADRID, BRAH, 78: EDITION, STUDY AND SURVEY OF HIS INFLUENCE \\ IN LATIN ANNALISTIC LITERATURE OF MEDIEVAL SPAIN
}

\author{
JOSE CARLOS MARTíN \\ Universidad de Salamanca
}

\begin{abstract}
Resumen: Se estudian y editan en este artículo unos anales de mártires transmitidos por Madrid, BN, 10029 y, en una segunda redacción inédita, por Madrid, BRAH, 78. Además se examina su posible datación y origen, sus fuentes y su influencia en la literatura analística latina de la Península Ibérica. Se ofrecen asimismo nuevas ediciones de los denominados Chronicon Rotense alterum y Chronicon paruum Ambrosianum.
\end{abstract}

Palabras clave: latín; anales; hagiografía; Hispania medieval.

\begin{abstract}
The scholar analyzes and publishes the Latin annals of martyrs transmitted in Madrid, BN, 10029 and, in an unpublished second version, Madrid, BRAH, 78. He also examines the possible date and origin, sources and influence in the Latin annals of Iberian Peninsule. Finally, this paper offers new editions of the so-called Chronicon Rotense alterum and Chronicon paruum Ambrosianum.
\end{abstract}

Keywords: Latin; annals; hagiography; Medieval Spain.

\section{SUMARIO}

1. Las Eras in quo martires passi sunt del códice de Azagra.- 2. Los inéditos Annales martyrum del códice de Roda.- 3. La analística latina catalana.- 4. La analística latina castellano-leonesa.5. La analística latina portuguesa.- 6 . Conclusión.

Este trabajo está dedicado a dos piezas minúsculas a medio camino entre la hagiografía y la historiografía, una de ellas inédita ${ }^{1}$. Se trata, en efecto, de unos tex-

\footnotetext{
${ }^{1}$ Este estudio ha sido realizado dentro del Proyecto de Investigación FFI2009-09134.

Abreviaturas utilizadas: BHL = Bibliotheca Hagiographica Latina Antiquae et Mediae Aetatis, 2 vols., Bruxelles, 1898-1899 (Subsidia Hagiographica, 6) (reimp. en 1 vol., 1992) + Bibliotheca Hagiographica Latina Antiquae et Mediae Aetatis. Novum Supplementum, H. FNOS (ed.), Bruxelles, 1986 (Subsidia Hagiographica, 70); CPL = Eligius DEKKERS y Aemilius GAAR, Clavis Patrum Latinorum, Steenbrugis, $1995^{3}$ (Corpus Christianorum); DHEC = Diccionari d'història eclesiàstica de Catalunya, R. CORTS BLAY, J. Galtés Pujol, A. MANENT Segimon (dirs.), 3 vols., Barcelona, 1998-2001; DHEE = Diccionario de Historia Eclesiástica de España, Q. AldeA VAQUero, T. MARín MARTíneZ, J. ViVes Gatell (dirs.), 4 vols. + 1 vol. de suplemento, Madrid, 1972-1987; Díaz = Manuel Cecilio DíAZ Y DíAZ, Index Scriptorum Latinorum Medii Aevi Hispanorum, 2 vols., Salamanca, 1958-1959 (Acta Salmanticensia, Filosofía y
} 
tos breves que presentan una estructura analística, comenzando con el nacimiento de Jesucristo y llegando hasta la muerte de san Martín de Tours (†397). Su originalidad reside en el hecho de que únicamente se recogen en ellos noticias relacionadas con las muertes de los santos, en especial, de los mártires de la Iglesia. Se incluye además la indicación precisa del emperador responsable de la persecución, desde los tiempos de Tiberio (14-37) hasta los de Diocleciano (284-305) y Maximiano (286-305).

Si atendemos a los contenidos de estos dos opúculos, nos encontramos con unas obras sumamente peculiares, hasta el punto de que no he hallado noticia alguna de esta especie de subgénero de anales de los mártires ni en los manuales al uso sobre hagiografía ni en los que se ocupan de la analística medieval ${ }^{2}$.

\section{LAS ERAS IN QVO MARTIRES PASSI SVNT DEL CÓDICE DE AZAGRA}

La primera de estas composiciones se ha conservado en el famoso códice de Azagra (Madrid, BN, 10029), un ejemplar ejecutado en su mayor parte en el s. IX y verosímilmente en la región de Córdoba, pero que recibió la adición de unos folios en su parte final, cuando se encontraba ya en el norte de la Península Ibérica, en la región asturleonesa, en el s. $X^{3}$. En el cuaternión que agrupa los folios añadidos en el s. X, copiados por varias manos, en concreto, en el f. 144v, puede leerse una obrita que presenta el siguiente título: "In nomine Domini incipiunt eras, in quo martires passi sunt" (Díaz-)4. No se trata de un texto desconocido, pues fue publicado por Flórez en la España Sagrada ${ }^{5}$. No obstante, ha pasado desapercibido hasta que recientemente, y de forma merecida, Bautista ha llamado de nuevo la atención sobre éste y otros textos analísticos de la Hispania medieval ${ }^{6}$. El estudio de este investigador, lleno de ideas originales, está en el origen de este artículo.

Ofrezco, en primer lugar, una nueva edición del texto ${ }^{7}$ :

Letras, 13,1-2); PLS = Patrologiae Latinae cursus completus a J.-P. Migne editus et Parisiis, anno Domini 1844, excusus. Series Latina: Supplementum, A. HAMMAN, L. GuILlAumIN (eds.), 5 vols., Paris, 19581974 (reimp. 1990); RFHMA = Repertorium fontium historiae Medii Aevi, 11 vols., Roma, 1962-2007.

2 Por ejemplo: René AIGRAIN, L’hagiographie, ses sources, ses méthodes, son histoire, Paris, 1954; J. DubOIS, Les martyrologes du moyen âge latin, Turnhout, 1978 (Typologie des sources du moyen âge occidental, 26); Réginald GRÉGOIRE, Manuale di Agiologia. Introduzione alla letteratura agiografica, Fabriano, 1996 (Bibliotheca Montisfani, 12) y Michael MCCORMICK, Les annales du haut moyen âge, Turnhout, 1975 (Typologie des sources du moyen âge occidental, 14).

${ }^{3}$ Sobre este manuscrito vid. Manuela VendREll PEÑARANDA, Estudio del códice de Azagra, Biblioteca Nacional ms. 10029, "Revista de Archivos, Bibliotecas y Museos", 82 (1979), pp. 655-705; M. C. DÍAZ Y DÍAZ, Manuscritos visigóticos del sur de la Península. Ensayo de distribución regional, Sevilla, 1995, pp. 130-134 (Publicaciones de la Universidad de Sevilla. Historia y Geografía, 11); Agustín Millares CARlo, Corpus de códices visigóticos, 2 vols., Las Palmas de Gran Canaria, 1999 (edición póstuma de M. C. DíAZ Y DíAZ, A. M. Mundó, J. M. Ruiz AsEncio, B. CASAdo QUINTANILLA y E. LECUONA RIBOT), vol. 1, $\mathrm{n}^{\circ}$ 167, pp. 117-118; Inventario general de manuscritos de la Biblioteca Nacional, vol. 14. (9501 a 10200), Madrid, 2000, pp. 300-301; Paulo F. ALBERTO, Eugenii Toletani Opera omnia, Turnhout, 2005 (CC SL 114), pp. 88-96.

${ }^{4}$ Señalo de este modo el hecho de que se trata de una obra no recogida en M. C. DíAZ Y DíAZ, Index Scriptorum.

${ }^{5}$ Enrique FlóREZ, España Sagrada, vol. 6, Madrid, 1751, pp. 347-350 (edición basada en el códice de Azagra).

${ }^{6}$ Francisco BAUTISTA, Breve historiografía: Listas regias y Anales en la Península Ibérica (siglos VII-XII), "Talia dixit", 4 (2009), pp. 113-190, [www1.unex.es/arengas/td4Bautista.pdf] [Consulta: 24/01/2010].

${ }^{7}$ He podido transcribir el texto directamente de Madrid, BN, 10029. A pesar de ello, en algunos pasajes la tinta está tan desgastada que las letras y números resultan imposibles de leer. Marco esos puntos del texto con corchetes del tipo \{\} . En ellos sigo las lecturas de Flórez. 
In nomine Domini incipiunt eras, in quo martires passi sunt.

(1) In era XXXVIIII ${ }^{\mathrm{a}}$. Ihs Xps filius Dei in Bethlem Iude nascitur ${ }^{8}$.

(2) In era XLII ${ }^{a}$. Erodes infantes occidi iussit'.

(3) In era LXVIIII ${ }^{a}$. Ihoannes babtiste decollatus est sub imperio Tiberii cesaris.

(4) In era LXVIIII ${ }^{a}$. Xps appassione uenit anno Tiberii XVIII ${ }^{10}$.

(5) In era CVIII ${ }^{a}$. sanctus Petrus et Paulus passi sunt sub Nerone cesare ${ }^{11}$.

(6) In era CXXXVIIII ${ }^{\mathrm{a}}$. adsumtus est sanctus Ihoannes apostolus sub Troiano inperatore ${ }^{12}$

(7) In era CXLVI ${ }^{a}$. Simon Cleope filius crucifigitur in Iherosolima sub Troiano inperatore ${ }^{13}$.

(8) In era CLVI . passi sunt III. filie sancte Soffie, Spes, Fides et Karitas, et Euleterius episcopus sub Adriano imperatore.

(9) In era CCVII ${ }^{\mathrm{a}}$ passus est sanctus Felix episcopus Nolensis et sancta Felicitas cum VIIm. filiis suis sub Marceliano et Antonino inperatoris.

(10) In era CCXVIIII ${ }^{\mathrm{a}}$ passa est [est] sancta Eugenia sub Comodo imperatore.

(11) In era CCLX $X^{\mathrm{a}}$ passi sunt ss. Facundus et Primitibus sub Attico et Protestato consulibus.

(12) In era CCLXVI ${ }^{\mathrm{a}}$. passa est sancta Cecilia sub Alaxandro imperatore.

(13) In era CCXLIII ${ }^{a}{ }^{14}$ passi sunt sanctus Xistus episcopus et Laurentius diaconus et Ipolitus et sanctus Xpoforus sub Decio imperatore.

(14) In era CCXLVIII . passus est sanctus Ciprianus episcopus sub Valeriano et Gallieno imperatoribus.

(15) In era CCXLVIIII ${ }^{\mathrm{a}}$. passi sunt sanctus Fructuosus episcopus, Agurius et Eulogius ${ }^{15}$ sub Valeriano et Gallieno imperatoribus.

(16) In era $\mathrm{CCCX}^{\mathrm{a}}$. passa est sancta Columba sub Aureliano inperator.

(17) In era CCCXIII ${ }^{\mathrm{a}}$. passus est sanctus Crisantus et Darie sub Numeriano inperatore.

(18) In era CCCXXVI $I^{\mathrm{a}}$. passi sunt sanctus Iulianus et sanctus Sabastianus et sanctus Adrianus sub Diocletiano et Maximiano.

(19) In era CCCXXVIII . passus est sanctus Romanus sub Diocletiano et Maximiano imperatoribus.

${ }^{8}$ Posible fuente: Crónica de Eusebio-Jerónimo (CPG $3494+C P L 615$ c), a. 1 a. C. (p. 169) (ed. Rudolf HELM, Eusebius Werke, vol. 7. Die Chronik des Hieronymus, Berlin, $1956^{2}$ [Die griechischen christlichen Schriftsteller der ersten Jahrhunderte, 47]); o la Crónica de Próspero de Aquitania (CPL 2257), c. 359 (ed. Theodor Mommsen, Monumenta Germaniae Historica, Chronica minora I, Berlin, 1892 [Auctores Antiquissimi, 9], pp. 385-485).

${ }^{9}$ Posible fuente: Crónica de Eusebio-Jerónimo, a. 2 (p. 169); o la Crónica de Próspero de Aquitania, c. 362 .

${ }^{10}$ Posible fuente: Crónica de Eusebio-Jerónimo, a. 31 (p. 174); o la Crónica de Próspero de Aquitania, c. 388.

${ }^{11}$ Posible fuente: Crónica de Eusebio-Jerónimo, a. 69 (p. 185); o la Crónica de Próspero de Aquitania, c. 466

${ }^{12}$ Posible fuente: Crónica de Eusebio-Jerónimo, a. 100 (p. 193); o la Crónica de Próspero de Aquitania, c. 550

${ }^{13}$ Posible fuente: Crónica de Eusebio-Jerónimo, a. 107 (p. 194); o la Crónica de Próspero de Aquitania, c. 558

${ }^{14}$ La fecha que aquí transcribo "CCXLIII" apenas se lee en el manuscrito. Flórez tampoco leyó bien la fecha: "CC...III".

${ }^{15}$ Transcribo así la abreviatura "elgs" del códice. 
(20) In era CCCXLVI . passus est sanctus Vincentius et sanctus Felix, Cosmas et Damianus et Todosia, Eolalia Emeritense, Iustus et Pastor sub Diocletiano et Maximiano.

(21) In era CCCCIII ${ }^{\text {a }}$ Quiriacus episcopus cum matre sua Anna sub Iuliano cesare. Ipse crucem Domini inuenit cum matre Constantini imperatoris. Eo tempore erat sancti Antonii mo\{nachi\}.

(22) In era CCCCXLVII ${ }^{\mathrm{a}}{ }^{16}$ Obiit sanctus Martinus episcopus Turonice sedis. (23) In era CCC $\{$ CXLVI $\} I^{\mathrm{a}}$. XVIIII. mense martio a Diocletiano et Maximiano $\{$ inperatores $\}$ eclesie subuerse sunt ${ }^{17}$.

Estas Eras, que Bautista califica con razón de anales de mártires, serían, a juicio de este estudioso, una obra elaborada en Córdoba en el s. IX que acaso debería ser puesta en relación con el contexto martirial de esa región y época ${ }^{18}$. Antes Domínguez del Val había atribuido esta obrita al obispo Máximo de Zaragoza (ca. 592-619), aunque sin argumento alguno ${ }^{19}$. Por mi parte, creo que ha de tenerse en cuenta que, como he señalado, la sección en la que se copia esta pieza en el códice de Azagra está formada por una serie de folios añadidos en la región asturleonesa. Vendrell Peñaranda insiste en el hecho de que los ff. 141-144 no son, en realidad, un verdadero cuartenión, sino una serie de folios más o menos independientes agrupados en un momento dado al final del manuscrito y convertidos en un cuaternión en el s. XII. El último de estos folios, el 144, se dejó, de hecho, en blanco en el recto, mientras que en el verso alguien añadió las citadas eras de los mártires. Dos siglos despues, otra mano copió en el recto de ese folio el epitafio de Pedro Coméstor ${ }^{20}$. De ahí que, si bien el contexto en el que estas Eras aparecen dentro de ese manuscrito sigue siendo más o menos cordobés, puesto que se han copiado algunos poemas de época mozárabe compuestos en Córdoba, no lo es de un modo exclusivo. De hecho, no es seguro que esta pieza en concreto lo sea. Pudo haber ocurrido, en efecto, que en lugar de llegar al reino asturleonés procedente del sur, se añadiese en el manuscrito en esa región tomándola de otro ejemplar existente en el norte peninsular.

Los santos y festividades honrados en esta pieza son los siguientes, con la fecha de su culto en los calendarios hispánicos medievales ${ }^{21}$ : (1) Natiuitas Domini (BHL $4151 \mathrm{~m}-4254 \mathrm{v}$ ) (25 de diciembre), (2) Innocentes martyres (BHL 4276-4278e) (8 de enero), (3) Iohannes Baptista (o Decollatio Iohannis Baptiste) (BHL 4290-4315e) (24 de septiembre), (4) Passio Domini (BHL 4151m-4254v), (5) Petrus et Paulus apostoli (BHL 6644-6688 y 6568s-6583, respectivamente) (29 de junio), (6) Iohannes apostolus et euangelista (o Adsumptio Iohannis apostoli) (BHL 4316-4328f) (29 de diciembre, especialmente), (7) Simon Cleopae apostolus (BHL 7749-7754) (1 de julio, especialmente), (8) Fides, Spes, Caritas et earum mater Sophia (Sapientia) mm. Romae

\footnotetext{
${ }^{16}$ La lectura "CCCCXLVI" es dudosa. Así leyó Flórez también.

${ }^{17}$ Posible fuente: Crónica de Eusebio-Jerónimo, a. 304 (p. 228); o la Crónica de Próspero de Aquitania, c. 966.

${ }^{18}$ F. BAUTISTA, Breve historiografía, pp. 146-147.

${ }^{19}$ Ursicino DOMÍNGUEZ DEL VAL, Herencia literaria de padres y escritores españoles de Osio de Córdoba a Julián de Toledo, in Repertorio de Historia de las Ciencias Eclesiásticas en España, vol. 1. Siglos III-XVI, Salamanca, 1967, pp. 1-85, en la p. 80 (Corpus Scriptorum Sacrorum Hispaniae. Estudios, 1).

${ }^{20}$ Vid. M. VendRell PeÑARANDA, Estudio del códice de Azagra, especialmente pp. 678 y 687.

${ }^{21}$ Son especialmente útiles los trabajos de José VIVES, Santoral visigodo en calendarios e inscripciones, "Analecta Sacra Tarraconensia", 14 (1941), pp. 31-58; y Pierre DAVID, Études historiques sur la Galice et le Portugal du VI au XII siècle, Lisboa-Paris, 1947, pp. 185-224 ("Le sanctoral hispanique"), (Collection Portugaise, 7).
} 
(BHL 2966-2973b) (29 de agosto) + Eleutherius ep. m. Romae (BHL 2450-2453c) (18 de abril), (9) Felix ep. Nolanus (BHL 2869) (27 de julio) + Felicitas cum septem filiis mm. Romae (BHL 2853-2855d) (23 de noviembre), (10) Eugenia m. Romae (BHL 2666-2670) (27 de diciembre), (11) Facundus et Primitiuus mm. in Galecia (BHL 2820-2821) (27 de noviembre), (12) Caecilia v. m. Romae (BHL 1495-1500) (22 de noviembre), (13) Sixtus II papa m. (BHL 7081-7812e) (10 de agosto) + Laurentius diac. m. Romae (BHL 4752-4789) (10 de agosto) e Hippolytus Romanus presb. (BHL 3960-3969a) (10 de agosto) + Christophorus m. in Lycia (BHL 1764-1780b) (10 de julio), (14) Cyprianus ep. Carthaginiensis (BHL 2037-2046d) (14 de septiembre), (15) Fructuosus ep. Tarraconensis, Augurius et Eulogius diac. (BHL 3196-3206) (21 de enero), (16) Columba uirgo m. apud Senones (BHL 1892-1896n) (31 de diciembre), (17) Chrysanthus et Daria mm. Romae (BHL 1787-1794) (12-13 de agosto), (18) Iulianus m. Antinoi in Aegypto (BHL 4529-4536d) (7 de enero) + Sebastianus m. Romae (BHL 7543-7549b) (19 de enero) + Hadrianus m. Nicomediae (BHL 3744-3745e) (16 de junio), (19) Romanus mon. m. Antiochiae (BHL 7297-7304d) (18 de noviembre), (20) Vincentius diac. Caesaraugustanus m. Valentiae (BHL 8627-8655d) (22 de enero) + Felix m. Gerundae (?) (1 de agosto) (BHL 2864-2868)22 + Cosmas et Damianus mm. Aegis in Cilicia (BHL 1967-1979b) (22 de octubre) + Theodosia v. m. Caesareae (BHL 8090-8092) (3 de abril) + Eulalia uirgo m. Emeritae (BHL 2699-2703) (10 de diciembre) + Iustus et Pastor mm. Compluti (BHL 4595) (6 de agosto), (21) Quiriacus (Iudas) ep. m. Hierosolymis (BHL 7022-7025f) (4 de mayo) + Antonius abb. in Thebaide (BHL 609-614) (17 de enero), (22) Martinus ep. Turonensis (BHL 5610-5666m) (11 de noviembre).

La noticia más antigua se refiere al nacimiento de Cristo (1) y la más reciente a la muerte de san Martín de Tours (22), lo que proporciona como terminus post quem de redacción el año 397. Tras esta entrada encontramos de forma sorprendente una noticia de fecha más temprana (23), pues se refiere a la persecución de la Iglesia en tiempos de Diocleciano (284-305) y Maximiano (286-305), que, no obstante, aparece datada de forma absurda en la era 448 (a. 410), quizás en un intento de justificar su posición tras la muerte de san Martín, fechada en el texto en la era 446 (a. 408). Es también diferente al resto de las entradas del texto porque no se refiere a ningún santo en concreto. Y es una de las pocas para las que puede proponerse con bastante verosimilitud una fuente concreta: la Crónica de Eusebio-Jerónimo (a. 304 [p. 228]) 23. Se diría que es una noticia añadida de forma secundaria al texto original. También podría ser una interpolación la referencia a san Antonio (21), por resultar extraña al estilo del texto y por no encontrarse, como se verá, en la recensio longior de las Eras ${ }^{24}$.

Llama asimismo la atención el hecho de que los santos no siempre aparecen agrupados tal y como se encuentran en los calendarios donde se les rinde culto. En algún caso, esta circunstancia encuentra una fácil explicación. Puede sospecharse, en efecto, que el apóstol Simón el Cananeo no aparece acompañado de Judas Tadeo (7) porque el autor de las Eras sigue, en ese caso en concreto, una fuente que no es un

\footnotetext{
${ }^{22}$ Podría tratarse también de Felix m. Romae (BHL 2878-2884m) (30 de agosto). Menos probable es su identificación con Felix m. Aquileiae (BHL 2860-2860d) (11 de junio), festividad que no he encontrado recogida en los calendarios hispánicos.

${ }^{23}$ Otra posibilidad sería la Crónica de Próspero de Aquitania, c. 967.

${ }^{24}$ Llama también la atención en esta noticia el hecho de que san Antonio no fue mártir, si bien tampoco lo fue san Martín de Tours, citado en la entrada siguiente. Según P. DAVID, Études historiques, p. 201, desde el s. V se introdujo en Occidente la práctica de considerar a los grandes ascetas como los iguales de los mártires, lo que explicaría la inclusión de estos dos santos confesores en estas Eras.
} 
calendario (probablemente la Crónica de Eusebio-Jerónimo o la de Próspero de Aquitania); y que san Julián de Antince (18) no es citado junto a su esposa Basilisa debido al hecho de que esta última no padeció el martirio.

Al margen de la referencia a san Antonio, que, como es dudosa, la dejaré a un lado, pero que presenta el sujeto del verbo en genitivo, hay otros dos genitivos que sugieren que en el origen de algunas de las noticias de este texto, que no parece de carácter litúrgico, está un calendario o un martirologio. Una es la entrada referida a san Juan Bautista (3), en la que el autor parece haber transformado un genitivo en el nominativo "Ihoannes", sin reparar en que habría debido transformar igualmente el calificativo siguiente "babtiste" en "babtista". El segundo ejemplo lo proporciona la entrada sobre los santos Crisanto y Daría (17) en la que también se ha escrito en nominativo el primero de los nombres ("Crisantus"), pero no el segundo ("Darie").

El uso de la era hispánica hace pensar en un origen peninsular, pero llama la atención el hecho de que se incluyan en la lista de los mártires citados algunos nombres de santos que no aparecen recogidos en los calendarios hispanolatinos medievales más antiguos. Por ejemplo, de acuerdo con la reconstrucción de P. David del hipotético calendario que representaría la tradición del santoral hispánico antes de mediados del s. XI, de los 32 santos citados en estas Eras, cuatro de ellos son mártires que no formarían parte de este santoral: "Spes, Fides et Karitas" (8), "sancta Felicitas cum VIIm. filiis suis" (9), "Crisantus et Darie" (17), "Quiriacus episcopus cum matre sua Anna" $(21)^{25}$. Es significativo asimismo que, atendiendo al examen de Fábrega Grau de la formación del denominado Pasionario hispánico, las pasiones de estos cuatro grupos de mártires no habrían entrado en esta compilación hasta el s. $\mathrm{XI}^{26}$. Por el contrario, todos estos mártires figuran en los martirologios franceses del s. IX de Adón de Vienne $(\dagger 875)^{27}$ y de Usuardo $(\dagger \text { ca. 877 })^{28}$. Además, con excepción de Fe, Esperanza y Caridad, los otros tres grupos de mártires figuran en el Martyrologium Hieronymianum (CPL 2031), compilado quizás en Burgundia en el s. VII ${ }^{29}$; y Felici-

${ }^{25}$ P. DAVID, Études historiques, pp. 196-201.

${ }^{26}$ Ángel FÁBrega GraU, Pasionario hispánico (siglos VII-XI), 2 vols., Madrid-Barcelona, 19531955 (Monumenta Hispaniae Sacra. Serie Litúrgica, 6), vol. 1, pp. 272-273.

${ }^{27}$ Jacques Dubois, Geneviève RenAud (ed.), Le Martyrologe d'Adon. Ses deux familles, ses trois recensions. Texte et commentaire, Paris, 1984 (Sources d'histoire médiévale), respectivamente: p. 243 (segunda familia), 1 de agosto ( $\$ 6$ "Romae, sanctarum virginum Spei, Fidei et Caritatis et matris earum Sapientiae, quae sub Adriano principe martyrii coronam adeptae sunt”); p. 390, 23 de noviembre ( $\$ 3$ "Eodem die, natale sanctae Felicitatis, matris septem filiorum martyrum, quae iubente Antonino decollata est pro Christo...); p. 402, 1 de diciembre ( $\$ 3$ "Natale sanctorum martyrum Chrysanti et Dariae, qui tempore Numeriani sub iudice Celerino Romae passi sunt...”); p. 147, 4 de mayo ( $\$ 6$ "Ipso die, beati Quiriaci, episcopi et martyris gloriosi, sub Iuliano imperatore"), y en la segunda familia el 1 de mayo, pp. 138-139 (\$3 “Item Hierosolymis, passio sancti Quiriaci episcopi qui et Iudas vocatus est. Hic per multa tormentorum genera palmam martyrii gloriose consecutus est").

${ }^{28}$ J. Dubois (ed.), Le Martyrologe d'Usuard. Texte et commentaire, Bruxelles, 1965 (Subsidia hagiographica, 40), respectivamente: p. 276, 1 de agosto ( $\$ 4$ "Item Romae, passio sanctarum uirginum Spei, Fidei et Caritatis et matris earum Sapientiae, quae sub Adriano principe martyrii coronam adeptae sunt"); p. 346, 23 de noviembre (\$2 Eodem die sanctae Felicitatis matris septem filiorum martyrum, quae iubente Antonio decollata est pro Christo"); p. 351, 1 de diciembre ( 11 "Romae, natalis sanctorum martyrum Chrisanti et Dariae virginis, qui post multarum quas pro Christo lucrati fuerant passiones, iussit sunt a Numeriano imperatore, via Salaria, in arenario deponi atque illic viventes terra et lapidibus obrui”); p. 223, 4 de mayo (\$2 "Ierosolimis, passio sancti Quiriaci episcopi, sub Iuliano").

${ }^{29}$ Sobre el origen y datación del Martyrologium Hieronymianum (CPL 2031), vid., por ejemplo, Jonathan P. CONANT, Europe and the African Cult of Saints, circa 350-900: An Essay in Mediterranean Communications, "Speculum", 85 (2010), pp. 1-46, p. 10. Para las noticias de los mártires aquí 
dad y Crisanto y Daría son recogidos igualmente en el martirologio conocido como el Anónimo de Lyon (anterior a 806) y en el de Floro de Lyon († ca. 860) ${ }^{30}$. Asimismo, en los calendarios hispánicos que he consultado, las primeras referencias a Felicidad y sus hijos se encuentran en calendarios de finales del s. XII de San Salvador de Oña y San Isidoro de León, en los que se ha advertido una fuerte influencia cluniacense ${ }^{31}$.

Así, si se tiene en cuenta, por un lado, que estas Eras fueron añadidas al códice de Azagra a comienzos del s. X en el norte peninsular y, por otro, que algunos de los mártires citados gozaban ya de culto por entonces en Francia, pero no en Hispania, quizás habría que buscar el origen de este texto en una región hispana en territorio cristiano y bajo influencia francesa. Si a ello se añade, como trataré de mostrar, que la influencia más temprana de esta pieza, bajo la forma de la recensio longior transmitida por el códice de Roda (Madrid, BRAH, 78), se pone de manifiesto en el noreste peninsular, en una amplia zona que se extiende desde el territorio riojano hasta el catalán, es evidente que la Cataluña medieval, fuertemente influenciada por el reino franco, podría haber sido la región de origen de este texto. En cuanto a su datación, aunque ha sido fechado en el s. $\mathrm{VI}^{32}$, no me parece que existan argumentos decisivos para situarlo en una fecha o en otra. Los únicos datos seguros son su terminus post quem en el a. 397 (fecha de la muerte de san Martín de Tours) y su terminus ante quem a comienzos del s. X (fecha de ejecución del folio del códice de Azagra que lo transmite). Es posible, no obstante, que algún especialista en hagiografía o liturgia pueda añadir nuevas precisiones en relación con el origen y datación de estas Eras.

estudiados, vid. la edición de Henri QUENTIN, Hippolyte DeLEHAYE, Acta Sanctorum Nouember II/2. Commentarius perpetuus in Martyrologium Hieronymianum ad recensionem Henrici Quentin, $O$. S. B., Bruxelles, 1931, p. 615, 23 de noviembre ("Felicitatis"); p. 436, 12 de agosto ("Romae sanctorum Crissanti et Darie et qui cum eis passi sunt..."; p. 222, 1 de mayo ("Hierosolima natale sancti Iudae sive Quiriaci episcopi").

${ }^{30}$ Para las referencias del Anónimo de Lyon y de Floro de Lyon, vid. la edición de J. DUBOIS, G. RENAUD, Édition pratique des martyrologes de Bède, de l'Anonyme lyonnais et de Florus, Paris, 1976 (Bibliographies, Colloques, Travaux préparatoires), p. 212, 23 de noviembre (\$2 "Sanctae Felicitatis matris septem filiorum martyrum, quae iubente Antonino decollata est pro Christo"); p. 217, 29 de noviembre ( $\$ 3$ "Romae, natale sanctorum Chrysanti et Dariae virginis, quae ad praedicationem eius conversa est. Qui, post multorum quos pro Christo lucrati fuerant passiones, a Celerino urbis praefecto iussi sunt via Salaria in arenario deponi atque illic viventes terra et lapidibus obrui").

${ }^{31}$ En todos los calendarios hispánicos que conozco, la festividad se incluye el 23 de noviembre. El de San Salvador de Oña ha sido editado por Baudoin de GAIFFIER, Un calendrier franco-hispanique de la fin du XII siècle, "Analecta Bollandiana", 69 (1951), pp. 282-323, en la p. 317 "Felicitatis mar."; y el del monasterio de San Isidoro de León, por Ana SUÁREZ GONZÁLEZ, Dos calendarios litúrgicos leoneses de la segunda mitad del siglo XII, in Memoria Ecclesiae XXV. Hagiografía y archivos de la Iglesia. Santoral hispano-mozárabe en las diócesis de España. Actas del XVIII Congreso de la Asociación celebrado en Orense (Segunda parte) (9 al 13 de septiembre de 2002), (A. HEVILLA BALLINA, ed.), Oviedo, 2004, pp. 161-186, el calendario que aquí interesa se lee en las pp. 175-186, y la referencia a santa Felicidad aparece en la p. 185. Otros dos calendarios que recogen esta festividad son uno de San Juan de las Abadesas de 1235, editado por José MARTíNEZ GÁZQUEZ, Santoral del calendario del s. XIII contenido en el Liber Regius del Museo episcopal de Vic, "Revista Catalana de Teología”, 6 (1981), pp. 161-174 (reimp. in José Martínez Gázquez, eum legentem uidimus. Selección de artículos y estudios, vol. 1, Bellaterra, 2009, pp. 99-112), en la p. 172; y otro de la diócesis de Barcelona del s. XIV, editado por José JANINI, Dos calendarios de Barcelona (siglos X y XIV), "Revista Catalana de Teología”, 3 (1978), pp. 313-325, en las pp. 316-325, y el pasaje que aquí interesa en la p. 324.

${ }^{32}$ RFHMA, vol. 3, p. 380: "Chronicón de las Eras de los Mártires”. 


\section{LOS INÉDITOS ANNALES MARTYRVM DEL CÓDICE DE RODA}

Una versión ampliada de estas Eras, caracterizada por la adición de un catálogo de diez emperadores perseguidores de los cristianos al comienzo del texto, de un buen número de santos en su parte central y de una serie de noticias en honor de san Jerónimo por el final, se ha transmitido en otro famoso ejemplar, el códice de Roda: Madrid, Biblioteca de la Real Academia de la Historia, 78, ejecutado (en la parte que aquí interesa) a comienzos del s. XI probablemente en Nájera ${ }^{33}$. Es Bautista, de nuevo, quien ha llamado la atención sobre esta pieza, que se lee en el f. 193ra-va del citado manuscrito y que aquí denominaré Annales martyrum codicis Rotensis ${ }^{34}$. Un apógrafo parcial de este ejemplar, copiado a finales del s. XVIII, se conserva asimismo en la Biblioteca de la Real Academia de la Historia, bajo la signatura 9/5619 (olim 9-28-5). Contiene los anales a los que me he referido en los ff. $41 \mathrm{v}-42 \mathrm{r}^{35}$. Ofrezco a continuación la editio princeps de esta obrita de acuerdo con la versión del códice de Roda, en la que señalo, en las entradas 1-22, mediante caracteres expandidos las novedades del texto con respecto a las eras del códice de Azagra:

Nomina imperatorum qui xpistianis persequuti sunt.

AI. Sub Nerone.

AII. Sub Domitiano.

AIII. Sub Traiano.

AIIII. Sub Antonino.

Av. Sub Seuero.

AvI. Sub Maximiano.

AVII. Sub Decio.

AvIII. Sub Valeriano.

AvIIII. Sub Aureliano.

Ax. Sub Diocletiano.

\footnotetext{
${ }^{33}$ Sobre este manuscrito, vid. José Ma . LACARRA, Textos navarros del Códice de Roda, in Estudios de Edad Media de la Corona de Aragón. Sección de Zaragoza. I, Zaragoza, 1945 (Escuela de Estudios Medievales, Trabajos y documentos, 1; Publicaciones de la Sección de Zaragoza, 1), pp. 193-301; M. C. DÍAZ Y DÍAZ, Libros y librerías en la Rioja altomedieval, Logroño, 1979 (1991) (Biblioteca de Temas Riojanos), pp. 32-42; Elisa RuIZ GARcía (dir.), Catálogo de la Sección de Códices de la Real Academia de la Historia, Madrid, 1997, pp. 395-405; Ángel J. MARTín DUQUE, Primera parte. El reino de Pamplona, in La España cristiana de los siglos VIII al XI, vol. 2. Los núcleos pirenaicos (718-1035): Navarra, Aragón, Cataluña, (M. RIU Y RIU, coord.), Madrid, 1999 (Historia de España Menéndez Pidal, 7), pp. 39-266, en las pp. 66-74; A. Millares CARLO, Corpus de códices visigóticos, vol. 1, n 210, pp. 139-142; Elisa de CARLOS VILlaMARín, El códice de Roda (Madrid, BRAH 78) como compilación de voluntad historiográfica, "Edad Media", 12 (2011), pp. 119-142.

${ }^{34}$ Vid. F. BAuTiSTA, Breve historiografía, p. 147. Con anterioridad, ya E. Ruiz en su catálogo de los códices de la BRAH había señalado la existencia de estos anales, vid. E. RUIZ GARCíA (dir.), Catálogo de la Sección de Códices, p. 398.

35 Vid. Antonio Rodríguez ViLLA, Catálogo general de manuscritos de la Real Academia de la Historia (1910-1912), versión en pdf descargable en <www.rah.es/biblioteca.htm> [Consulta: 24/01/2011], pp. 103-104. Está formado por II hojas de guarda +5 ff. sin numerar (el último en blanco) con el título, la noticia del modelo y el índice de los contenidos +86 folios a línea tirada + III hojas de guarda. En la portada se lee: "Colección de diferente cronicones antiguos que se hallan en un códice gótico M. S. en vitela a fines del siglo IX, el qual parece haber sido de la Santa Iglesia de Roda. Copiados fielmente de su original y demostrados sus caracteres para el uso de la Real Academia de la Historia de orden de su director el ilustrísimo Señor Don Pedro Rodríguez Campomanes por Francisco Xavier de Santiago Palomares. Año de M. DCC. LXXX."
} 
(1) In era XXX VIII ${ }^{\mathrm{a}}$ Ihesus Xps. filius Dei in Betlem Iude nascitur et incarnatio eius dicitur.

(2) Era XL II ${ }^{\mathrm{a}}$ Erodes infantes occidi iussit.

(3) Era LX VIIII I Iohannes babtiste decolatus ab Herode inperio Thiberi cesaris.

(4) Era LXXI Ihesus Xps. ad passionem anno Thiberi .XVIII ${ }^{\circ}$. Et in era LXXII $^{\mathrm{a}}$ post ascensionem Domini $\mathrm{III}^{\mathrm{o}}$ kalendas ianuarias sanctus Iacobus apostolus frater sancti Iohannis apostoli et euangeliste ab Erode rege decollatus est Ierosolimam.

(5) Era C VIIII ${ }^{\mathrm{a}}$ sanctus Petrus et Paulus passi sunt sub Nerone cesare.

(6) Era C XXXVIIII adsumptus est sanctus Iohannes apostolus et euangeliste[e] sub Traiano imperatore.

(7) Era CL VII ${ }^{\mathrm{a}}$ passe sunt tres filie sancte Sophie, Spes, Fides et Caritas, et Eleuterius episcopus sub Adriano imperatore.

(8) Era CC VII ${ }^{\mathrm{a}}$ passi sunt sanctus Felix Nolensis episcopus et sancta Felicitas et VIIem filius sub Marcho et Antonino imperatoribus.

(9) Era CC XVIIII ${ }^{\text {a }}$ conuersa est sancta Eugenia sub Quomodo imperatore.

(10) Era $<C C>$ LX $^{\mathrm{a}}$ passi sunt sanctus Facundus et Primitibus sub Adtico et Pretestato consulibus.

(11) Era CC LXVI ${ }^{\mathrm{a}}$ passa est sancta Cecilia sub Alexandro inperatore.

(12) Era CC LX $<$ L $>$ III $^{\mathrm{a}}$ passi sunt sanctus Tirsus, Sistus episcopus, Laurentius, Ypolitus et sanctus Xpistoforus sub Decio inperatore.

(13) Era CC LXL VIIII ${ }^{\mathrm{a}}$ passus est sanctus Ciprianus episcopus sub Valeriano et Gallecio inperatoribus, et sancta Eugenia.

(14) Era CCC X III ${ }^{\mathrm{a}}$ passa est sancta Columba sub Aureliano imperatore.

(15) Era CCC XXV passi sunt sanctus Crisanctus et Daria sub Numeriano inperatore.

(16) Era CCC XXVII ${ }^{\mathrm{a}}$ passus est sanctus Iulianus, sanctus Sabastianus, sanctus Adrianus sub Diocletiano et Maximiano imperatoribus.

(17) Era CCC XXVIII ${ }^{\mathrm{a}}$ passus est sanctus Romanus sub Diocletiano et Maximiano imperatoribus.

(18) Era CCC XL VI ${ }^{a}$ passi sunt sanctus Vincentius, Cucuphas, Felix, Pantaleon, Cosmas, Damianus, Teodosia, Eolalia, Iustus et Pastor, Agonensius. Item Iulianus. Item Vincentius, Sauina et Xpistete. Item Eolalia, Agnes, Cresconius, Acap sub Diocletiano et Maximiano imperatoribus.

(19) Era CCCC III ${ }^{\mathrm{a}}$ passus est sanctus Quiriacus episcopus cum matre sua Anna sub Iuliano cesare. Ipse crucem Domini inuenit cum Elena, matrem Constantini inperatoris.

(20) Era CCCC XL VII ${ }^{\mathrm{a}}$ obiit sanctus Martinus Turnorum episcopus. Iheronimus transtulit cronica Eusebi etatis sue anno XL VIII ${ }^{\mathrm{o}} .{ }^{36}$

\footnotetext{
${ }^{36}$ Esta anotación ha sido hecha con toda verosimilitud a partir de la información suministrada por la Crónica de Próspero de Aquitania. De acuerdo con esta obra, Jerónimo nació en el a. 304, contando desde la pasión del Señor en adelante: c. 1031. "CCCIV Basso et Ablabio", c. 1032. "Hieronimus nascitur"; y se fija el fin de la Crónica de Eusebio-Jerónimo en el a. 351, c. 1162 "CCCLI Valente VI et Valentiniano II...", y c. 1166 "Hucusque Hieronimus presbyter ordinem praecedentium digessit annorum: nos quae consecuta sint adicere curavimus". Si se hace el cálculo, restando 351-304, el resultado es que Jerónimo habría concluido la traducción del texto a la edad de 47 años. La diferencia de una unidad se puede explicar fácilmente si se piensa que es probable que el autor de esta entrada tuviese a su disposición un manuscrito de Próspero con algún tipo de variantes en las dataciones que diese como resultado 48 (por ejemplo: "CCCIII" por "CCCIIII").
} 
(21) Post $\mathrm{VII}^{\mathrm{O}}$ uero annis in Bethlem hauitare cepit, egregio ingenio et studio serbiens tote eclesie per annos $\mathrm{XX}^{\mathrm{i}} \mathrm{V}^{\mathrm{e}}$ et mortuus etatis sue anno LXXVI $^{\circ}$ sub die $\mathrm{V}^{\circ}$ kalendas septembris. Teodosio ter decies et Valentinianno ter. ${ }^{37}$

(22) Cognoscitur ergo Iheronimus natiuitate maior esse beato Agustino annos XIIII ${ }^{\mathrm{m}}$.

Como he señalado, estos anales comienzan con un catálogo de los diez perseguidores de la Iglesia hasta los tiempos de Constantino I (306-337). Las abreviaturas "AI... AII... AIII" deben entenderse como " $\mathrm{I}^{\mathrm{a}}$ persecutio... II $\mathrm{I}^{\mathrm{a}}$ persecutio... III" ${ }^{\mathrm{a}}$ persecutio..." etc. De acuerdo con un antiguo trabajo de Grumel, que incluye un cómodo cuadro comparativo que recoge las listas de los emperadores perseguidores de los cristianos en los principales autores cristianos de la Antigüedad Tardía, como Lactancio, Orosio, Próspero de Aquitania y otros, los Nomina imperatorum del códice de Roda se corresponderían con el catálogo fijado por Orosio ${ }^{38}$. No obstante, Grumel no tiene en cuenta en su estudio un texto fundamental de la historiografía cristiana tardoantigua y medieval: la Crónica de Eusebio-Jerónimo, en la que ya puede encontrarse este mismo elenco de diez perseguidores y que es, con toda probabilidad, la fuente de este texto. Estos diez perseguidores son los siguientes: 1. Nerón (54-68), 2. Domiciano (81-96), 3. Trajano (98-117), 4. Marco Aurelio Antonino (161-180), 5. Septimio Severo (193211), 6. Maximino el Tracio (235-238), 7. Decio (249-251), 8. Valeriano (253-260), 9. Aureliano (270-275) y 10. Diocleciano (284-305) ${ }^{39}$. Este catálogo está, sin duda, en el origen del que se lee al comienzo de la Chronica Naierensis (Díaz 996): lib. I, $1^{40}$.

Una rápida comparación de estos Nomina imperatorum con las eras del códice de Azagra revela de inmediato que estamos ante dos autores distintos. Lleva a esta conclusión la falta de coherencia que caracteriza a una y otra pieza: por un lado, hay tres emperadores de la lista de los perseguidores que no aparecen citados en las noticias de los mártires: el segundo, Domiciano; el quinto, Septimio Severo; y el sexto, Maximino el Tracio (citado como Maximiano); y por otro lado, varios de los

${ }^{37}$ Esta noticia procede también de la Crónica de Próspero de Aquitania, c. 1186 "Hoc tempore Hieronimus presbyter in Bethleem, toto iam mundo clarus, habitabat, egregio ingenio et studio universae ecclesiae serviens", c. 1272 "CCCXCIII. Theodosio VIIII et Constatio III", y en el año de estos cónsules se fecha la muerte de Jerónimo: c. 1274 "Hieronimus presbyter moritur anno aetatis suae XCI prid. kal. Octobris" (hay dos manuscritos, no obstante, que transmiten la variante "LXI"). Y más adelante en esa misma crónica se da noticia de los cónsules citados en estos anales: c. 1302 "CCCCIII. Theodosio XIII et Valentiniano III", situándose en ese momento el fallecimiento de Agustín de Hipona: c. 1304 "Aurelius Augustinus episcopus per omnia excellentissimus moritur V. k1. sept., libris Iuliani inter impetus obsidentium Wandalorum in ipso dierum suorum fine respondens et gloriose in defensione Christianae gratiae perseverans". Si se comparan los datos de las fechas de la muerte de Jerónimo y de Agustín, se observará que en los anales del códice de Roda se ha confundido el día y el año de la muerte de Jerónimo y Agustín, atribuyendo al primero los datos del segundo.

${ }^{38}$ Venance GRUMEL, Du nombre des persécutions païennes dans les anciennes chroniques, "Revue des Études Augustiniennes", 2 (1956), pp. 61-66.

${ }^{39}$ Los pasajes son los siguientes: a. 68 (p. 185): "Prima persecutio a Nerone"; a. 94 (p. 192): "II persecutio a Domitiano"; a. 107 (p. 194): "III persecutio a Traiano"; a. 166 (p. 205) (en tiempos de Marco Aurelio y Cómodo): "IIII persecutio"; a. 202 (p. 212) (en tiempos de Septimio Severo): "V persecutio"; a. 237 (p. 216) (en tiempos de Maximino el Tracio): "VI persecutio"; a. 252 (p. 218) (en tiempos de Decio): "VII persecutio"; a. 258 (p. 220) (en tiempos de Valeriano y Galieno): "VIII persecutio Valeriani”; a. 275 (p. 223) (en tiempos de Aureliano): "VIIII persecutio"; y a. 301 (p. 227) (en tiempos de Diocleciano): "X persecutio".

${ }^{40}$ Edición de Juan Antonio EstÉVEZ SolA, Chronica Hispana saeculi XII. Pars II. Chronica Naierensis, Turnhout, 1995 (CC CM 71A). Agradezco la referencia a F. Bautista. 
emperadores perseguidores de la noticia de los mártires no son incluidos en la lista inicial: Adriano (8), Marco Aurelio Antonino (citado como si se tratase de dos emperadores diferentes: Marceliano y Antonino) (9), Cómodo (10), Alejandro Severo (12) y Numeriano (17).

Más verosímil parece que el autor de este catálogo fuese el mismo que reelaboró las eras del códice de Azagra en la versión transmitida por el códice de Roda, interpolándolas y continuándolas por el final. Lleva a sustentar esta hipótesis el hecho de que el responsable de esta reescritura del texto sentía una gran admiración por Jerónimo de Estridón, a quien dedica las tres últimas noticias de estos segundos anales (20-22). En ellas hay incluso una referencia explícita a la traducción de Jerónimo al latín de la versión original en griego de la Crónica de Eusebio de Cesarea (20). A ello se añade el hecho de que la fuente de estas últimas entradas es, sin la menor duda, la Crónica de Próspero de Aquitania, transmitida en muchos manuscritos en compañía de la Crónica de Eusebio-Jerónimo. En consecuencia, es probable que el autor de esas últimas entradas tuviese a su disposición un códice que transmitiese tanto la Crónica de Eusebio-Jerónimo como la de Próspero de Aquitania, como es frecuente en la tradición manuscrita de estas obras.

Examinadas las adiciones del comienzo y del final de esta versión ampliada y reelaborada de las eras del códice de Azagra, veamos ahora los cambios introducidos en la versión rotense en las entradas dedicadas a los mártires. Los nuevos santos citados son los siguientes: (4) Iacobus Maior apost. filius Zebedaei, frater Iohannis (BHL 40564085) (30 de diciembre, especialmente), (12) Thyrsus m. in Asia (BHL 8277-8281) (28 de enero), (18) Cucufas m. Barcinone (BHL 1997-2000) (25 de julio) + Pantaleon $m$. Nicomediae (BHL 6429-6448) (19 de febrero) + Agaunenses martyres ${ }^{41}$ (BHL 57375764) (22 de septiembre) + Iulianus m. Antinoi in Aegypto ${ }^{42}$ (BHL 4529-4536d) (7 de enero) + Vincentius, Sabina et Christeta mm. Abulae (BHL 8619-8620) (28 de octubre) + Eulalia v. m. Barcinone ${ }^{43}$ (BHL 2693-2698) (12 de febrero) + Agnes v. m. Romae saec. III (BHL 156-167c) (20 de enero) + Chrysogonus m. Aquileiae ${ }^{44}$ (BHL 1795-1797) (24 de noviembre ó 1 de abril) + Agape v. m. Thessalonicae ${ }^{45}$ (BHL 118-120) (1 de abril en el único calendario hispánico que conozco que honra a esta santa).

Otras modificaciones del texto son el desplazamiento del martirio de santa Eugenia desde los tiempos de Cómodo (9) a los de Valeriano y su hijo Galieno (13) ${ }^{46}$, y cuatro omisiones, dos que atribuyo a meros saltos de ojo: la del apóstol Simón, que habría debido aparecer citado tras la entrada dedicada al apóstol Juan (6), y la de los santos Fructuoso, Augurio y Eulogio, que habrían debido citarse tras la entrada dedicada a Cipriano y Eugenia (13), y otras dos más difíciles de explicar, la de san Antonio abad (19) y la de la destrucción de las iglesias cristianas en tiempos de Diocleciano y

\footnotetext{
${ }^{41}$ En los anales citados como "Agonensius" por un error de transmisión.

${ }^{42}$ Ha de tratarse, sin duda, de este Julián, pese a que ya se encuentra citado más arriba en estos mismos anales en la entrada 16.

${ }^{43}$ En esta entrada n. ${ }^{\circ} 18$ el nombre de Eulalia aparece citado en dos ocasiones. La primera de ellas ha de referirse a Eulalia de Mérida, de acuerdo con la versión de las eras del códice de Azagra (20), aunque en estos anales no se añada el gentilicio. De ello deduzco que el segundo nombre se refiere a la otra Eulalia venerada en la Península Ibérica: Eulalia de Barcelona.

${ }^{44}$ Es el "Cresconius" de los anales, otra lectura corrupta.

${ }^{45}$ En los anales, sin duda, por un nuevo error de transmisión se lee "Acap".

${ }^{46}$ La falsa cronología del códice de Azagra, aquí corregida, se explica probablemente por los relatos martiriales consagrados a esta santa, donde, al comienzo de la narración, se sitúa la historia en tiempos del emperador Cómodo. Vid. la edición de la Passio s. Eugeniae (BHL 2666) en Á. FÁBREGA GRAU, Pasionario hispánico, vol. 2, pp. 83-98.
} 
Maximiano, noticias que, como he señalado más arriba, acaso no se encontraban en la versión original de las Eras transmitidas por el códice de Azagra, por lo que quizás no se trata realmente de omisiones y su ausencia deba explicarse por el hecho de que el autor de los anales del códice de Roda no las tenía en el texto de que dispuso. Según todos los indicios, las cuatro entradas de las eras de Azagra que no se leen en los anales del códice de Roda no se encontraban en el arquetipo al que remonta la tradición conocida de esta segunda obra, pues tampoco se incluye ninguna de ellas en los testimonios de la tradición indirecta.

La adición de la noticia dedicada al martirio de Santiago el Mayor (4) y el uso de la era hispánica sitúan el origen de estos anales en la Península Ibérica. Llama también la atención el hecho de que, entre las adiciones señaladas más arriba, los únicos mártires de origen hispano son los abulenses Vicente, Sabina y Cristeta (18) y dos santos barceloneses, Cucufate y Eulalia (18). Así, si la posible influencia de la liturgia francesa que he señalado al ocuparme de las eras del códice de Azagra me ha llevado a proponer como lugar de redacción de ese texto la región catalana, la presencia significativa ahora de dos santos honrados especialmente en Cataluña entre las tres nuevas incorporaciones de mártires peninsulares al texto apunta de nuevo a un origen catalán para estos anales, origen que me parece confirmado por la tradición indirecta de esta pieza, como se verá.

Otro aspecto de interés es que en las noticias dedicadas a los mártires hay tres nombres claramente corruptos en la entrada núm. 18: "Agonensius", un error por "Agaunenses"; "Cresconius", un error por "Crisogonus"; y, aunque es menos probante, "Acap", un error por "Agape". Esto indica que no estamos ante la versión original de esta obra, sino tan sólo ante una copia.

Para dar con las lecturas correctas hay que tener presentes varios textos:

- El Chronicon Rotense alterum (Díaz 1183), unos anales compilados en su versión final en Roda hacia 1205, pero en el que especialistas catalanes en el tema han distinguido una primera redacción de origen ripollés que concluiría hacia el último tercio del s. $\mathrm{XI}^{47}$. En este cronicón, del que ofreceré una nueva edición completa en este artículo, se lee en la entrada correspondiente a la era 347 (18) ${ }^{48}$ : "Passi sunt sanctus Vincencius, Felix, Pantaleon, Cosmas et Damianus, Thedosia, Eulalia, Iustus et Pastor, Agaunenses martires, Iulianus, Vincentius, Sabina, $\mathrm{X}^{\mathrm{e}}$ tes, Eulalia, Agnes, Grisogonus, Agapitus sub Diocletiano".

${ }^{47}$ Fue editado por Jaime VILlanuEVA, Viage literario a las iglesias de España, vol. 15, Madrid, 1851, pp. 332-335. Bibliografía principal: Fernando VALLS TABERNER, Els inicis de la historiografia catalana, in Obras selectas de Fernando Valls-Taberner, vol. 4. Estudios de historia medieval, Madrid-Barcelona, 1961, pp. 1-13 (= Matisos d'història i de llegenda, Barcelona, 1932 [reimp. Zaragoza, 1991], pp. 112-128), en la p. 9; Miquel COLl ALENTORN, La historiografia de Catalunya en el període primitiu, "Estudis Romànics", 3 (1951-1952), pp. 139-196 (reimp. in IDEM, Historiografia, Barcelona, 1991 [Textos i estudis de cultura catalana, 21; Obres de Miquel Coll i Alentorn, 1], pp. 11-62), en las pp. 157-158 y 160; Michel ZIMMERMANN, La prise de Barcelone par Al-Mansûr et la naissance de l'historiographe catalane, “Annales de Bretagne et des pays de l'Ouest”, 87 (1980), pp. 191-218 (= La presa de Barcelona per Al-Mansur i el naixement de la historiografia catalana, in IDEM, En els orígens de Catalunya. Emancipació política i afirmació cultural, Barcelona, 1989 [Llibres a l'abast, 248], pp. 71-97), en las pp. 210-211; Thomas N. BISSON, Unheroed Pasts: History and Commemoration in South Frankland before the Albigensian Crusades, "Speculum", 65 (1990), pp. 281-308, en las pp. 289-290; Josep M. SALRACH, Contribució dels monjos de Ripoll als orígens de la historiografia catalana: els primers cronicons, in Art i cultura als monestris del Ripollès: Santa Maria de Ripoll - Sant Joan de les Abadesses - Sant Pere de Camprodon. Ponències de la 1a. Setmana d'Estudis. Sessions del 16 al 18 de setembre de 1992, Montserrat, 1995 (Biblioteca Milà i Fontanals, 20), pp. 17-35, en las pp. 26-27; F. BAUTISTA, Breve historiografía, pp. 162-163.

${ }^{48}$ Cito por por mi propia edición de esta obra, que ofrezco más adelante en este mismo trabajo. 
- La Notitia martyrum (Díaz 572, CPL 2046b), un texto quizás del s. X, entrada n. ${ }^{\circ}$ 56 ${ }^{49}$ : "Gresogonius, Agape et Cionia et Erene. Passi sunt in Aquileia sub Diocleciano imperatore a Dulcito preside et Sisino comite".

Que estos "Agaunenses martyres" eran festejados con esta denominación en la liturgia medieval hispánica se ve confirmado por un martirologio de probable origen castellano fechado en el s. X, en el que, en la entrada correspondiente al 22 de septiembre, se incluye a los mártires agaunenses: "X kl. Sanctorum Aucanensium et in Acauno VI milia DC, Victoris" 50 ; y por tres calendarios de Silos de la segunda mitad del s. XI, en los que, el día 22 de septiembre, se festeja el natalicio de los "Scor(um) Acaunensium mr(um)" o "Scor(um) Agaonensium mr(um) Xpi." 51.

También Crisogono es honrado en varios calendarios hispanolatinos medievales. El testimonio más interesante, sin duda, es el de un calendario de Silos del a. 1052, en el que, el día 1 de abril, aparece citado junto a Ágape, como en la Notitia martyrum: "Sc(orum) Gregonii Agape Cion[i]e et Herene triu(m) sororu(m)" 52 . Además, su festividad aparece recogida otros calendarios, siempre con fecha 24 de noviembre: en un antiguo calendario hispano del s. IX (Díaz 527), "VIII Kal. Rome natale sancti Crisogoni Eleutheri Maximi Mametis" "53; en uno de Santa María de Ripoll del s. X, "VIII kl. dcbr. Crisogoni dies egipc." ${ }^{4}$; en otro de rito romano de San Millán de finales del s. XI, "VIII. Sci grisogoni mrum." 55 ; en otro de San Salvador de Oña de finales del XII, "VIII kal. Grisogoni mar." 56 ; y, en fin, en otro de la diócesis de Barcelona del s. XIV, "VIII. Grisogoni epi et mr. Dedictio s. Marchi bar. se." ${ }^{57}$. Asimismo en los pasionarios de origen hispánico, la pasión de Crisogono aparece unida a la de Ágape, como en Paris, BnF, n. a. lat. 2179 (s. XI, Silos): "Passio b. mm. Chrysogoni, Agapae, Chioniae et Irenae trium sororum... die IIII nonas apriles", transmitida en los ff. 142-148r ${ }^{58}$. Este relato habría entrado a formar parte del Pasionario hispánico en el s. XI, según Fábrega Grau ${ }^{59}$.

${ }^{49}$ Cito por Luis VÁzQuez de PARga, El Pasionario Hispánico de San Millán de la Cogolla. (Intento de restitución), "Bullettino dell’ Archivio Paleografico Italiano", n. s. 2-3 (1956-1957), pp. 367-377, en las pp. 373-377. Vives se limita a reproducir la edición de V. de Parga, vid. J. VIVES, El supuesto Pasionario Hispánico de San Millán de la Cogolla, "Hispania Sacra", 12 (1959), pp. 445-453, en las pp. 450-453 (reimpr. en PLS 4,1889-93).

${ }^{50}$ Cito por B. de GAIFFIER, Un abrégé hispanique du martyrologe hiéronymien, "Analecta Bollandiana”, 82 (1964), pp. 5-35, en las pp. 7-28 (p. 20).

${ }^{51}$ Han sido editados por J. VIVES y Á. FÁBREGA GRAU, Calendarios hispánicos anteriores al siglo XII, "Hispania Sacra”, 2 (1949), pp. 119-146 y 339-380, en las pp. 356-361 (p. 360) y pp. 374-379 (p. 378).

${ }^{52}$ Cito por J. Vives, Á. FÁBrega GraU, Calendarios hispánicos, pp. 356-361 (p. 357).

${ }^{53}$ Heribert PlenKERS, Das Martyrolog des Cod. Esc. I.III.13, in Untersuchungen zur Überlieferungsgeschichte der ältesten lateinishen Mönchsregeln, München, 1906, pp. 91-100 (Quellen und Untersuchungen zur lateinischen Philologie des Mittelalters, 1), mutilado por el comienzo. El pasaje que aquí interesa se lee en la p. 99.

${ }^{54}$ J. VIVES, Á. FÁBREGa GRAU, Calendarios hispánicos, pp. 123-134 (p. 133).

${ }^{55}$ J. JANINI, Dos calendarios emilianenses del siglo XI, "Hispania Sacra", 15 (1962), pp. 177-195, en las pp. 183-194 (el pasaje en la p. 193). De este calendario existe una edición más reciente, pero menos fiable, de Jean VEZIN, Un calendrier franco-hispanique de la fin du XIe siècle, "Bibliothèque de l'École des Chartes", 121 (1963), pp. 5-25 (el pasaje en la p. 24).

${ }^{56}$ B. de GAIFFIER, Un calendrier franco-hispanique, p. 317.

${ }^{57}$ J. JANINI, Dos calendarios de Barcelona, pp. 316-325 (p. 324).

${ }^{58}$ Catalogus codicum hagiographicorum Latinorum antiquiorum saeculo XVI qui asservantur in Bibliotheca Nationali Parisiensi, vol. 3, Bruxelles, 1893, pp. 476-487, la referencia a esta pasión en la p. 479.

${ }^{59}$ Á. FÁBrega GraU, Pasionario hispánico, vol. 1, pp. 225-237, con mención de esta pasión en la p. 227. 
Por el contrario, ningún mártir de nombre Agapito puede ponerse en relación con las persecuciones de Diocleciano y Maximiano. En este último caso, la variante "Agapitus" del Chronicon Rotense alterum parece un intento erróneo de solucionar una lectura del tipo "Acap", como se lee en el códice de Roda, que podría haber sido igualmente la del modelo que conoció el autor del citado cronicón.

Bautista ha propuesto que el códice de Roda es el modelo utilizado en la redacción del Chronicon Rotense alterum, invirtiendo así totalmente el sentido del origen de la historiografía catalana primitiva en latín, que no habría surgido en Ripoll, para extenderse desde allí hasta territorio aragonés, sino que habría recibido en un primer momento la influencia de la historiografía surgida en las regiones más occidentales, como probaría la utilización del códice de Roda en la elaboración de este cronicón ${ }^{60}$. Esta tesis resulta controvertida si atendemos a la tradición manuscrita, pues obligaría a pensar que el compilador-autor de la redacción más antigua del Chronicon Rotense alterum habría sabido reconocer en la forma absurda "Agonensius", que no corresponde a mártir alguno, una referencia a los "Agaunenses martyres", lo que encuentro poco probable. Se diría, por el contrario, que este autor catalán se sirvió de un códice que contenía una versión de los anales de los mártires del códice de Roda libre de algunas de las malas lecturas presentes en este manuscrito, como "Agonensius" y "Cresconius". Esto sugiere, en consecuencia, que el modelo de este texto conocido en Cuixá y Ripoll estuvo libre de algunas de las corrupciones del ejemplar de esta misma obra que fue utilizado en Nájera. En efecto, además de las dos malas lecturas ya indicadas, puede señalarse todavía un tercer error en la referencia a los emperadores en el poder en el año de la muerte de san Cipriano, donde en el Chronicon Rotense alterum se lee "sub Valeriano et Gallieno" (14) junto con las eras del códice de Azagra (14) y frente al error de los anales del códice de Roda (13) "sub Valeriano et Gallecio". Esto vendría así a confirmar, a mi juicio, las tesis existentes sobre la difusión de la historiografía catalana latina primitiva, tal y como se leen, por ejemplo, en los trabajos de Coll Alentorn y Salrach ${ }^{61}$.

Puesto que estos anales fueron utilizados en la composición del denominado Chronicon alterum Riuipullense (Díaz 1045), podrían fecharse quizás entre el s. IX y mediados del s. X.

\section{LA ANALÍSTICA LATINA CATALANA}

\subsection{El Chronicon alterum Riuipullense (Díaz 1045)}

Otro importante argumento, para mí incluso decisivo, en favor de la tesis aquí expuesta, a saber, que la pieza que he denominado Annales martyrum codicis Rotensis es más antigua que el códice de Roda, es el hecho de que estos anales fueron una de las fuentes utilizadas en la elaboración del denominado Chronicon alterum Riuipullense (Díaz 1045), terminado de componer hacia el año 1191 en Santa María de Ripoll, pero que habría conocido una primera redacción hacia el año 984 en San Miguel de Cuixá, de acuerdo con la tesis de Coll Alentorn, sostenida, a mi entender, sobre sólidos argumentos ${ }^{62}$. En efecto, si se acepta la existencia de una primera redac-

\footnotetext{
${ }^{60}$ F. BAUTISTA, Breve historiografía, p. 163.

${ }^{61}$ M. Coll Alentorn, La historiografia de Catalunya; J. M. SAlRACH, Contribució dels monjos de Ripoll.

${ }^{62}$ M. Coll AlEnToRn, La historiografia de Catalunya, pp. 155-157. Esta tesis ha sido aceptada, de hecho, de forma general por los especialistas en la historiografía latina catalana, como M. ZIMMERMANN, $L a$ prise de Barcelone, pp. 207-209; T. N. BISSON, Unheroed Pasts, pp. 287-288 y J. M. SALRACH, Contribució dels monjos de Ripoll, pp. 19-26. Bautista, por su parte, parece rechazar la existencia de esta primera redacción del Chronicon alterum Riuipullense hacia 984, vid. F. BAUTISTA, Breve historiografía, pp. 160-167.
} 
ción del Chronicon alterum Riuipullense fechada en 985, ésta sería anterior a la ejecución del códice de Roda. Reproduzco a continuación las primeras entradas de este cronicón hasta la muerte de Isidoro de Sevilla, de acuerdo con la única edición de que disponemos, obra de Villanueva y basada en un manuscrito de Ripoll desaparecido en el s. XIX ${ }^{63}$. Resalto las noticias que proceden de los anales del códice de Roda ${ }^{64}$ :

Era LXV./ a. 27. Pontius Pilatus Judaeam procurat.

Era LXVIIII. / a. 31. Joannes Baptista decollatur.

Era LXXI. / a. 33. Christus passus est et resurrexit, et Jacobus apostolus decollatur ${ }^{65}$.

Era LXXVII. / a. 39. Tiberius moritur, et Cajus Caligula regnat.

Era LXXVIII. / a. 40. Mathaeus evangelium scribit.

Era LXXXI. / a. 43. Claudius regnat.

Era LXXXII. / a. 44. Petrus Romam venit.

Era LXXXIII. / a. 45. Claudius... apostolus Romam venit.

47. Marcus evangelium scribit. Lucas evangelium scribit.

52. Fuit mortuus Octavianus LVI. annorum.

54. Tiberius filius ejus regnat.

70. Petrus et Paulus passi sunt Romae ${ }^{66}$.

71. Galba... regnat.

72. Vespasianus regnat.

73. Jerosolyma civitas subvertitur, Judaei et venunduntur.

81. Claudius regnat.

82. Titus regnat. Hic pius et facundus fuit.

84. Domitianus regnat. Hic secundus post Neronem christianos persequitur.

98. Joannes in Patmos relegatus, Apocalipsim scribit.

99. Nerva regnat.

100. Joannes apostolus assumptus est. Trajanus regnat ${ }^{67}$.

108. Passus est s. Ignatius.

119. Passi sunt Sapientie et Eleuterius episcopi. Helius Adrianus regnat.

140. Antonius Pius regnat.

222. Passi sunt sancti Primitivus et Facundus ${ }^{68}$.

228. Passa est sancta Cecilia ${ }^{69}$.

228. Passi sunt Crisantus et Daria ${ }^{70}$.

291. Passus est s. Georgius.

300. Passus est s. Romanus ${ }^{71}$.

308. Passi sunt Vincentius, Felix, Eulalia, Agnes, Justus et Pastor, Eulalia, Cosmas, Damianus ${ }^{72}$.

${ }^{63}$ M. COll Alentorn, La historiografia de Catalunya, pp. 155-157.

${ }^{64}$ J. VillanueVA, Viage literario a las iglesias de España, vol. 5, Madrid, 1806, pp. 241-249, que se sirvió de un manuscrito de Ripoll desaparecido en el año 1835.

${ }^{65}$ Fuente: Annales martyrum codicis Rotensis 4.

${ }^{66}$ Fuente: Annales martyrum codicis Rotensis 5.

${ }^{67}$ Fuente: Annales martyrum codicis Rotensis 6.

${ }^{68}$ Fuente: Annales martyrum codicis Rotensis 10.

${ }^{69}$ Fuente: Annales martyrum codicis Rotensis 11.

${ }^{70}$ Fuente: Annales martyrum codicis Rotensis 15.

${ }^{71}$ Fuente: Annales martyrum codicis Rotensis 17.

${ }^{72}$ Fuente: Annales martyrum codicis Rotensis 18. 


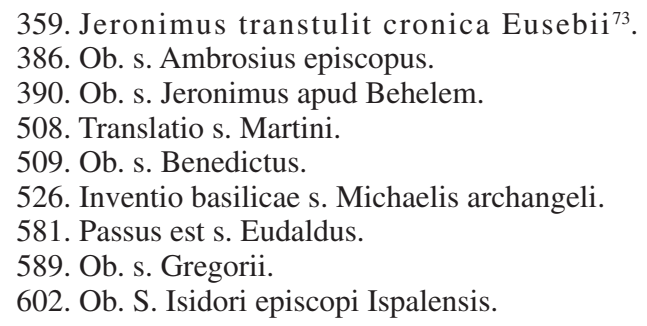

Entre las entradas coincidentes con los anales del códice de Roda, las más significativas son las de los a. 308 y 359, porque no pueden proceder de las eras del códice de Azagra. Por otro lado, resulta de interés observar que, como los anales de Roda, y a diferencia de las eras de Azagra, el Chronicon alterum Riuipullense no incluye las entradas correspondientes al apóstol Simón y a los mártires Fructuoso, Augurio y Eulogio. Lo mismo ocurre en el caso del Chronicon Rotense alterum, lo que confirma que se trata de unas omisiones propias del arquetipo al que remontan los modelos utilizados por los autores de estos textos. Como he señalado más arriba, no creo, sin embargo, que estas omisiones respondan al deseo deliberado de un copista. Es más probable atribuirlas sencillamente a un error de transmisión, probablemente a un salto de ojo, favorecido por el sistema de datación de este tipo de anales, en que es muy fácil confundir dos entradas de años semejantes, dejando la primera o la segunda sin copiar, según sea que el error se produzca a partir de la fecha en números romanos o de la última palabra de la entrada (con frecuencia "imperatore " o "imperatoribus", o el nombre de un emperador que se repite en varias entradas).

$\mathrm{Si}$ aceptamos, en consecuencia, la tesis de Coll Alentorn de la existencia de una primera redacción del Chronicon alterum Riuipullense hacia 984, ya fuese ésta elaborada en Cuixá o en Ripoll, debemos admitir la presencia de un volumen de la recensión larga de los anales del códice de Roda en territorio catalán a mediados del s. X, algunos años antes, en consecuencia, de la inclusión de esta obrita en el citado manuscrito.

\subsection{El Chronicon Rotense alterum (Díaz 1183)}

Este ejemplar de los Annales martyrum codicis Rotensis que circulaba por Cataluña en el s. X, o uno muy semejante a él, habría sido utilizado también algo menos de un siglo después de la redacción del Chronicon alterum Riuipullense en la composición en Ripoll del denominado Chronicon Rotense alterum (entradas 1-20), al que ya me he referido, que habría conocido una primera redacción hacia el último cuarto del s. XI. De este cronicón ripollés existen dos ediciones, una de J. de la Canal de 1836 y otra de J. Villanueva de $1851^{74}$. Dado que ambas son defectuosas, ofrezco a continuación mi propia edición de este cronicón, basada en el códice Lérida, Archivo Capitular, Roda 29 (olim 11), la parte que aquí interesa es del s. XIII, ff. 204ra-208vb (188ra-192vb de la antigua foliación $)^{75}$ :

\footnotetext{
${ }^{73}$ Fuente: Annales martyrum codicis Rotensis 20.

${ }^{74}$ Respectivamente: José de la CANAL, España Sagrada, vol. 46, Madrid, 1836, pp. 339-343 (esta edición se ha venido confundiendo con la del denominado Chronicon Rotense primum [Díaz 1186], del s. XIII, que, en realidad, se encuentra en las pp. 343-345); y J. VILLANUEVA, Viage literario a las iglesias de España, vol. 15, pp. 332-335.

${ }^{75}$ Vid. José JANINI, Manuscritos litúrgicos de las Bibliotecas de España, vol. 2. Aragón, Cataluña y Valencia (Publicaciones de la Facultad Teológica del Norte de España. Sede de Burgos, 38/2),
} 
(1) Era XXX ${ }^{a}$ VIII. Ihesus Xps filius Dei natus est ${ }^{76}$.

(2) Era XL ${ }^{\mathrm{a}}$. II ${ }^{\mathrm{a}}$. Herodes infantes occidit ${ }^{77}$.

(3) Era LX ${ }^{\mathrm{a}}$ VIIIII. Iohannes babtista decollatur ${ }^{78}$.

(4) Era LXX ${ }^{\mathrm{a}}$. Ihesus Xpistus passus est ante ${ }^{79}$ Tiberi XVIII $^{80}$.

(5) Era ipsa $\operatorname{LXX}^{\mathrm{a}} I^{\mathrm{a}}$. Post ascensionem Domini, VIII. kalendas agusti, Iacobus apostolus, frater Iohannis apostoli decollatus est ${ }^{81}$.

(6) Era C ${ }^{\mathrm{a}}$ VIII ${ }^{\mathrm{a}}$. Petrus et Paulus passi sunt Rome ${ }^{82}$.

(7) Era $C^{a} X X X^{a} V_{I I I}{ }^{a}$. Iohannes apostolus assumptus est ${ }^{83}$.

(8) Era C ${ }^{\mathrm{a}} \mathrm{L}^{\mathrm{a}}$ VII ${ }^{\mathrm{a}}$. Passa est Sapientia cum filiabus et Eleuterius episcopus sub Adriano imperatore ${ }^{84}$.

(9) Era $\mathrm{CC}^{\mathrm{a}} \mathrm{VII}^{\mathrm{a}}$. Passus est Felix Nolensis episcopus et beata Felicitas cum VII. filiis suis sub Marcho et Antonino ${ }^{85}$.

(10) Era $C^{\mathrm{a}}$. XVIII ${ }^{\mathrm{a}}$. Conuersa est sancta Eugenia sub Comodo imperatore ${ }^{86}$.

(11) Era CC ${ }^{\mathrm{a}}$ LX $X^{\mathrm{a}}$ Passi sunt s. Primitiuus et Facundus sub Atico et Pretextato consulibus ${ }^{87}$.

(12) Era CC ${ }^{a}$ LXVI$^{\mathrm{a}}$. Passa est sancta Cecilia sub Alexandro imperatore et Almachio prefecto ${ }^{88}$.

(13) Era CC LXVII. Passi sunt sanctus Tirsus et sanctus Sixtus episcopus, Laurentius, Ypolitus, $\mathrm{X}^{\circ}$ forus sub Decio ${ }^{89}$.

Burgos, 1980, n 557 (pp. 144-146); Marius BERnARDO, "Salterio, Himnario y Oficio rimado de san Raimundo", en Hispania Vetus. Manuscritos litúrgico musicales de los orígenes visigóticos a la transición francorromana (siglos IX-XII), S. ZAPKE (ed.), Bilbao, 2007, pp. 324-325. Existe un apógrafo parcial poco conocido de este manuscrito: Madrid, Biblioteca de la Real Academia de la Historia, 9/3969 (olim 9-21-3), del s. XVIII. Está compuesto por 390 folios + IV hojas de guarda. El Chronicon Rotense alterum aparece copiado en los ff. 6r-9v, precedido de este título "Necrologio copiado del f. 18 de un breviario manuscrito en vitela que existe en la santa yglesia de Roda catedral de Rivagorza". A continuación se copia en los ff. 10r-11v el denominado Chronicon Rotense primum (Díaz 1186), tomado de Lérida, AC, Roda 29, ff. 202v-203v. Los restantes folios contienen un extenso comentario en español de estos dos cronicones, entrada por entrada. Sobre este ejemplar, perteneciente a la colección de Manuel Abad y Lasierra, vid. además A. RoDRíGUEZ VILLA, Catálogo general, p. 2.

${ }^{76}$ Fuente: Annales martyrum codicis Rotensis 1.

${ }^{77}$ Fuente: Annales martyrum codicis Rotensis 2.

${ }^{78}$ Fuente: Annales martyrum codicis Rotensis 3.

${ }^{79}$ ante: anno intellege.

${ }^{80}$ Fuente: Annales martyrum codicis Rotensis 4.

${ }^{81}$ Fuente: Annales martyrum codicis Rotensis 4.

${ }^{82}$ Fuente: Annales martyrum codicis Rotensis 5.

${ }^{83}$ Fuente: Annales martyrum codicis Rotensis 6.

${ }^{84}$ Fuente: Annales martyrum codicis Rotensis 7.

${ }^{85}$ Fuente: Annales martyrum codicis Rotensis 8.

${ }^{86}$ Fuente: Annales martyrum codicis Rotensis 9.

${ }^{87}$ Fuente: Annales martyrum codicis Rotensis 10.

${ }^{88}$ Fuente: Annales martyrum codicis Rotensis 11 . Aunque la fuente son, como señalo, los anales del códice de Roda, en el Chronicon Rotense alterum se añade el nombre del prefecto Almaquio, una precisión que parece tomada del relato de la pasión, la Passio Valeriani, Tiburtii, Maximi et Ceciliae (CPL 2171, BHL 1495) (ed. en Á. FÁBREGA GRAU, Pasionario hispánico, vol. 2, pp. 25-40). Pero ¿estaba ya en los anales que conoció el compilador de esta primera parte del Chronicon Rotense alterum o es adición suya? Esta precisión y la corrección de la fecha de la muerte de Jerónimo en la entrada 20 son las dos principales modificaciones de este cronicón con respecto a su fuente para esta parte del texto. Una última diferencia con respecto a los anales del códice de Roda es la omisión de san Cucufate entre los mártires de la entrada 18, pero creo que puede atribuirse verosímilmente a un mero error de copia.

${ }^{89}$ Fuente: Annales martyrum codicis Rotensis 12. 
(14) Era CC ${ }^{\mathrm{a}}$ LX VIIII. Passus est Ciprianus episcopus et sancta Eugenia sub Valeriano et Gallieno ${ }^{90}$.

(15) Era $\mathrm{CCC}^{\mathrm{a}} \mathrm{XIII}{ }^{\mathrm{a}}$. Passa est sancta Columba sub Aureliano imperatore ${ }^{91}$. (16) Era $C^{2} C^{a} X X^{a} V^{a}$. Passi sunt Grisantus et Daria sub Numeriano imperatore $^{92}$.

(17) Era $\mathrm{CCC}^{\mathrm{a}} \mathrm{XX}^{\mathrm{a}}$ VII ${ }^{\mathrm{a}}$. Passi sunt Iulianus, Sebastianus, Adrianus sub Diocletiano ${ }^{93}$.

(17) Era $\mathrm{CCC}^{\mathrm{a}} \mathrm{XXX}^{\mathrm{a}}$ VIII ${ }^{\mathrm{a}}$. Passus est Romanus sub Diocleciano imperatore $^{94}$.

(18) Era CCC XL VII. Passi sunt sanctus Vincencius, Felix, Pantaleon, Cosmas et Damianus, Thedosia, Eulalia, Iustus et Pastor, Agaunenses martires, Iulianus, Vincentius, Sabina, $X^{\mathrm{e}}$ tes, Eulalia, Agnes, Grisogonus, Agapitus sub Diocletiano ${ }^{95}$.

(19) Era CCCC $^{\mathrm{a}}$. III $^{\mathrm{a}}$. Passus est Ciriacus episcopus cum matre sua Anna sub Iuliano cesare. Ipse est qui crucem Domini inuenit cum Helena, matre Constantini imperatoris ${ }^{96}$.

(20) Era CCCC XC.VII. Obiit sanctus Martinus Turonorum episcopus. Iheronimus transtulit cronica Eusebii etatis sue anno $\mathrm{XL}^{\circ} \cdot \mathrm{V}^{\mathrm{o}}$. Post $\mathrm{VII}{ }^{\mathrm{os}}$. uero annos in Bethleem habitare cepit, egregio ingenio et studio seruiens tote ecclesie per annos $\mathrm{XX}^{\mathrm{m}} \mathrm{V}^{\mathrm{e}}$. et mortuus est etatis sue annos LXX VII. sub die pridie kalendas octobris ${ }^{97}$.

(21) Era DCCCC LX IIII $^{\mathrm{a}}$. Passus est sanctus Pelagius sub Durahaman preside $^{98}$.

(22) Annus Domini DCCCC ${ }^{0} X^{0} V^{0}$ quando ipse fuit natus ${ }^{99}$.

(23) Anno DCCCC $^{\circ} \mathrm{LXX}^{\circ}$. Obiit domnus Arnulfus episcopus Gerundense et abbas huius cenobii ${ }^{100}$.

\footnotetext{
${ }^{90}$ Fuente: Annales martyrum codicis Rotensis 13.

${ }^{91}$ Fuente: Annales martyrum codicis Rotensis 14.

${ }^{92}$ Fuente: Annales martyrum codicis Rotensis 15.

${ }^{93}$ Fuente: Annales martyrum codicis Rotensis 16.

${ }^{94}$ Fuente: Annales martyrum codicis Rotensis 17.
}

${ }^{95}$ Fuente: Annales martyrum codicis Rotensis 18. En la lista se omite Cucufate, probablemente por un simple error de copia.

${ }^{96}$ Fuente: Annales martyrum codicis Rotensis 19.

${ }^{97}$ Fuente: Annales martyrum codicis Rotensis $20+21$. En esta entrada se da la fecha correcta de la muerte de Jerónimo, probablemente como resultado de una corrección culta del texto.

${ }^{98}$ La lectura "Durahaman" es una confusión por Abderramán: Abderramán III, emir de los territorios árabes de Hispania de 912 a 961. Vid., por ejemplo, la edición de la Passio s. Pelagii (BHL 6617) en Pilar Riesco ChUeCA, El Pasionario Hispánico. (Introducción, Edición crítica y Traducción), Sevilla, 1995 (Publicaciones de la Universidad de Sevilla. Filosofía y Letras, 131), pp. 308-320, c. 1: "Vita uel passio sancti Pelagii martiris, qui passus est Cordoba ciuitate sub Abdirrahaman rege, die $\mathrm{VI}^{\mathrm{D}}$ kalendas iulias", y c. 12: “...Igitur hic beatissimus Pelagius etate circiter tredecim et semis passu est annorum Cordoba, ut dictum est, in ciuitate, Abderrhaman rege imperante, die uidelicet dominica, hora decima, sexto kalendas iulias era DCCCCLXIII ${ }^{\mathrm{a}}$." La noticia se ha tomado, verosímilmente, de la pasión del santo.

${ }^{99}$ En esta entrada se produce una clara modificación en la compilación de este cronicón, pues en ella comienza a datarse el texto por los años de la encarnación. En esta primera línea se da simplemente la equivalencia de la era 964, en que se fecha el martirio de san Pelayo, con el año de la encarnación 926. Es, sin duda, la explicación correcta, propuesta por M. ZIMMERMANN, La prise de Barcelone, p. 210.

${ }^{100}$ Arnulfo († 970), abad de Ripoll (948-970) y obispo de Gerona (954-970). Vid. M. C. DíAZ Y DíAZ, Arnulfo, DHEE, vol. 1, p. 96; y Josep M. MARQUÈs PlanaGuMÀ, Arnulf, DHEC, vol. 1, pp. 118-119. 
(24) Anno DCCCC LXX VIII. Aduentus corporis sancti Eualdi martiris.

(25) Anno DCCCC LX ${ }^{\circ}$ VIIII.

(26) Anno DCCCC LXXX'. $\mathrm{V}^{\circ}$. Capta fuit Barchinona a Sarracenis.

(27) Anno DCCCC XC ${ }^{\circ} I^{\circ}$. obiit Borrellus comes Barchinone.

(28) Anno $\mathrm{M}^{\mathrm{O}} \mathrm{II}^{\mathrm{O}}$. Oliba comes factus est monacus, postea abbas et episcopus.

(29) Anno $\mathbf{M}^{\circ}$. III ${ }^{\circ}$. factum est prelium in Albesa cum Sarracenis, ubi Berengarius episcopus Elensis perimitur.

(30) Anno $\mathbf{M}^{\circ}$. VIIII ${ }^{\circ}$. obiit Seniofredus abbas Rippullensis. Cuius Oliba monacus succesit.

(31) Anno $\mathrm{M}^{\mathrm{o}}$. $\mathrm{X}^{\mathrm{o}}$. Obiit Ermengaudus, comes Urgelli, apud Cordubam et Arnulfus episcopus et Odo episcopus et multi alii potentes cum eis.

(32) Anno $\mathrm{M}^{\circ}$. XVII ${ }^{\circ}$. Raimundus comes Barchinone.

(33) Anno $\mathbf{M}^{\circ}$. XX $\mathrm{X}^{\circ}$. Obiit Bernardus comes ${ }^{101}$.

(34) Anno $M^{\circ}$. XXX ${ }^{\circ} I^{\circ}$. Obiit Rodebertus rex.

(35) Anno M. ${ }^{\circ} \mathrm{XXX}^{\mathrm{O}} \mathrm{II}^{\mathrm{o}}$. Dedicatio sancte Marie de Ripull.

(36) Anno $\mathrm{M}^{\circ} . \mathrm{XXX}^{\circ}$. $\mathrm{V}^{\mathrm{o}}$. Obiit Berengarius comes Barchinone et Sancius rex Castelle.

(37) Anno $\mathrm{M}^{\circ} . \mathrm{XXX}^{\circ} \mathrm{VII}^{\circ}$. Obiit Ermengaudus, comes Urgelli peregrinus.

(38) Anno $\mathrm{M}^{\mathrm{o}} \mathrm{XXX}^{\mathrm{o}} \mathrm{VIII}^{\mathrm{o}}$. Dedicatio sancti Petri sedis Vici et sancte Marie Gerunde ${ }^{102}$.

(39) Anno M ${ }^{\circ} \cdot X^{\circ}$. Dedicatio sancte Marie sedis Urgelli.

(40) Anno $\mathrm{M}^{\circ} \mathrm{LX}^{\circ}$. VII ${ }^{\circ}$. Obiit domnus Oliba episcopus et abbas Riuipullensis.

(41) Anno M ${ }^{\circ} . L^{\circ}$ II $^{\circ}$. Obiit Guillelmus comes Besellun Crassus.

(42) Anno M $^{\circ}$. L ${ }^{\circ}$ IIII $^{\circ}$. Garsias rex interfectus est.

(43) Anno $\mathrm{M}^{\circ} . \mathrm{L}^{\mathrm{O}} \mathrm{VIIII}^{\circ}$. Aduentus sanctorum Iusti et Pastoris Narbone.

(44) Anno $M^{\circ} L^{\circ}$. Obiit Enrichus rex et successit Philipus.

(45) Anno $\mathrm{M}^{\mathrm{o}} \mathrm{LX}^{\mathrm{o}} \mathrm{V}^{\mathrm{o}}$. Capta fuit ciuitas Barbastri.

(46) Anno $\mathrm{M}^{\mathrm{o}} \mathrm{LX}^{\mathrm{O}} \mathrm{VI}^{\circ}$. Ermengaudus comes Urgelli interemptus est a Sarracenis. Obiit Fredelandus rex.

(47) Anno $\mathrm{M}^{\mathrm{O}} \mathrm{LX}^{\mathrm{O}} \mathrm{VII}^{\circ}$. Obiit Raimundus comes Cerritanie.

(48) Anno $\mathrm{M}^{\mathrm{O}} \mathrm{LXX}^{\mathrm{o}} \mathrm{V}^{\mathrm{o}}$. Obiit Guillelmus episcopus Urgelli ${ }^{103}$.

(49) Anno M ${ }^{\circ}$ LXXX $^{\circ}$. Pascha II ${ }^{\circ}$. idus aprilis.

(50) Anno $M^{\circ} \operatorname{LXXX}^{\circ} I^{\circ}$. Pascha $I^{\circ}$ nonas aprilis.

(51) Anno $M^{0}$ LXXX $^{\circ}$ II $^{\circ}$. Pascha VIII. kalendas madii. Raimundus comes occissus est ${ }^{104}$.

(52) Anno $M^{\circ}$ LXXX $^{\circ}$ III $^{\circ}$. Pascha idus aprilis.

(53) Anno $M^{\circ} \operatorname{LXXX}^{\circ} \mathrm{IIII}^{\circ}$. Pascha II $\mathrm{II}^{\circ}$. kalendas aprilis.

(54) Anno $M^{0} \operatorname{LXXX}^{\circ} V^{\circ}$. Pascha XII ${ }^{\circ}$. kalendas madii. Gregorius papa obit.

${ }^{101}$ Esta última palabra ha sido añadida sobre la línea.

${ }^{102}$ Una nueva palabra añadida sobre la línea.

${ }^{103}$ Guillermo Guifredo, obispo de Urgel (1041-1075), vid. Benigne MARQUÈs SALA, Guillem Guifré, DHEC, vol. 2, p. 335; Cebrià BARAUT, Jesús CASTElls, B. MARQUÈs y Enric Moliné, Episcopologi de l'Església d'Urgell, segles VI-XXI, "Urgellia", 14 (1998-2001), pp. 7-136, en las pp. 42-43 (las pp. 31-52, dedicadas a los obispos de Urgel hasta el s. XIII, son reproducidas en C. BARAUT, Els bisbes d'Urgel [531-1203], in IDEM, Església i bisbat d'Urgell. Recull de treballs, La Seu d'Urgell, 2003, pp. 159-186, la referencia a Guillermo Guifredo en las pp. 173-174).

${ }^{104}$ El conde de Barcelona Ramón Berenguer II (1076-1082), asesinado en diciembre de 1082. 
(55) Anno $\mathrm{M}^{\circ} \mathrm{LXXX}^{\circ} \mathrm{VI}^{\circ}$. Pascha nonas aprilis.

(56) Anno ${ }^{\circ}{ }^{2 X X X}{ }^{\circ} V_{I I}{ }^{\circ}$. Pascha $V^{\circ}$. kalendas aprilis. Arabes uenerunt in Ispania ubi multos xpianorum peremerunt ac ipsorum plurimis peremptis reuersi sunt.

(57) Anno $\mathrm{M}^{\mathrm{o}}$. LXXX ${ }^{\mathrm{o}}$. VIII ${ }^{\mathrm{o}}$. Pascha $\mathrm{X}^{\mathrm{O}} \mathrm{VI}^{\mathrm{o}}$. kalendas $\mathrm{m}^{\mathrm{a}} \mathrm{i}$.

(58) Anno $M^{\circ}$ LXXX $^{\circ}$ VIIII ${ }^{\circ}$. Pascha kalendis aprilis. Captum fuit Montson VIII. kalendas iulii a Petro rege.

(59) Anno $\mathrm{M}^{\circ} \mathrm{XC}^{\mathrm{o}}$. Pascha $\mathrm{XI}^{\circ}$ kalendas madii.

(60) Anno $\mathrm{M}^{\mathrm{o}} \mathrm{XC}^{\mathrm{o}} \mathrm{I}^{\mathrm{o}}$. Pascha idus aprilis.

(61) Anno $\mathrm{M}^{\mathrm{o}} \mathrm{XC}^{\mathrm{o}} \mathrm{II}^{\mathrm{o}}$. Pascha $\mathrm{V}^{\mathrm{o}}$. kalendas aprilis. Obiit Ermengaudus comes Urgelli et Bernardus Guillelmus episcopus. Post cuius mortem duo episcopi sunt ordinati per contentione in sede Urgelli.

(62) An. $\mathrm{M}^{\text {us }} \mathrm{XC}^{\mathrm{us}} \mathrm{III}^{\mathrm{us}}$. Pascha kalendas $\mathrm{m}^{\mathrm{a}} \mathrm{i}$.

(63) Anno $\mathrm{M}^{\mathrm{o}} \mathrm{XC}^{\mathrm{o}} \mathrm{IIII}^{\circ}$. Pascha idus aprilis. Obiit Sancius rex et Raimundus Dalmacii episcopus ${ }^{105}$.

(64) Anno $\mathrm{M}^{0} \mathrm{XC}^{\mathrm{o}} \mathrm{V}^{\mathrm{o}}$. Pascha VIII. kalendas aprilis. Obiit Guillelmus comes Ceritanie et Bertrandus episcopus Barchinone et Dalmatius archiepiscopus Narbone.

(65) Anno $\mathrm{M}^{\mathrm{O}} \mathrm{XC}^{\mathrm{o}} \mathrm{VI}^{\mathrm{o}}$. Pascha idus aprilis. Concilium Urbani papa.

(66) Anno $\mathrm{M}^{\circ} \mathrm{XC}^{\mathrm{o}} \mathrm{VII}^{\circ}$. Pascha nonas aprilis. Obiit Salomon episcopus Rote. Capta est ciuitas Oscha et ciuitas Iherusalem.

(67) Anno $\mathrm{M}^{\mathrm{o}} \mathrm{XC}^{\mathrm{o}} \mathrm{VIII}^{\circ}$. Pascha $\mathrm{V}^{\circ}$. idus aprilis et fuit captum Calasanz $\mathrm{VIII}^{\circ}$. kalendas setembris.

(68) Anno $\mathrm{M}^{\mathrm{O}} \mathrm{XC}^{\mathrm{O}} \mathrm{VIIII}^{\mathrm{O}}$. Pascha IIII ${ }^{\circ}$. idus aprilis.

(69) Anno $\mathrm{M}^{\circ} \mathrm{C}^{\mathrm{o}}$. Pascha kalendas aprilis et fuit capta ciuitas Barbastri.

(70) Anno $\mathrm{M}^{\mathrm{o}} \mathrm{C}^{\mathrm{o}} \mathrm{I}^{\mathrm{o}}$. Pascha $\mathrm{XI}^{\mathrm{o}}$. kalendas madii. Pontius episcopus dedicauit ecclesia sancte Marie et sancti Vincentii de Barbastro.

(71) Anno $\mathrm{M}^{\mathrm{o}} \mathrm{C}^{\mathrm{o}} \mathrm{II}^{\mathrm{O}}$. Pascha VIII. idus aprilis et Ermengaudus comes occisus est in Mulieruça ${ }^{106}$.

(72) Anno $\mathrm{M}^{\mathrm{O}} \mathrm{C}^{\mathrm{O}} \mathrm{III}^{\mathrm{O}}$. Pascha $\mathrm{IIII}^{\circ}$ kalendas aprilis.

(73) Anno $\mathrm{M}^{\mathrm{o}} \mathrm{C}^{\mathrm{o}} \mathrm{IIII}^{\circ}$. Pascha XV kalendas madii. Obiit Pontius episcopus et Petrus rex Aragonis.

(74) Anno $M^{0} C^{\circ} V^{0}$. Pascha $V^{0}$. idus aprilis.

(75) Anno $\mathrm{M}^{\mathrm{o}} \mathrm{C}^{\mathrm{o}} \mathrm{VI}^{\mathrm{o}}$. Pascha VIII. kalendas aprilis.

(76) Anno $\mathrm{M}^{\circ} \mathrm{C}^{\mathrm{o}} \mathrm{VII}^{\circ}$. Pascha XVIII ${ }^{\circ}$. kalendas mai.

(77) Anno $\mathrm{M}^{\mathrm{O}} \mathrm{C}^{\mathrm{O}} \mathrm{VIII}^{\circ}$. Pascha nonas aprilis. Obiit Philipus rex.

(78) Anno $\mathrm{M}^{\circ} \mathrm{C}^{\mathrm{O}} \mathrm{VIIII}{ }^{\circ}$. Pascha VII kalendas mai. Obiit Illefonsus imperator.

(79) Anno $\mathrm{M}^{\mathrm{o}} \mathrm{C}^{\mathrm{o}} \mathrm{X}^{\mathrm{o}}$. Pascha $\mathrm{IIII}^{\circ}$. idus aprilis. Obiit Arnaldus episcopus Ausone et Bernardus episcopus Iherunde ${ }^{107}$.

(80) Anno $\mathrm{M}^{\circ} \mathrm{C}^{\mathrm{o}} \mathrm{XI}^{\circ}$. Pascha $\mathrm{IIII}^{\circ}$ nonas aprilis. Obiit Bernardus comes Barchinone.

(81) Anno $\mathrm{M}^{\circ} \mathrm{C}^{\mathrm{o}} \mathrm{XII}^{\circ}$. Pascha $\mathrm{XI}^{\circ}$. kalendas mai.

(82) Anno $\mathrm{M}^{\circ} \mathrm{C}^{\mathrm{o}} \mathrm{XIII}$. Pascha VIII ${ }^{\circ}$. kalendas aprilis.

(83) Anno $\mathrm{M}^{\mathrm{O}} \mathrm{C}^{\mathrm{o}} \mathrm{XIIII}^{\circ}$. Pascha $\mathrm{IIII}^{\circ}$. kalendas aprilis. Hoc anno intrauit comes Raimundus in Maioricas.

(84) Anno $\mathrm{M}^{\circ} \mathrm{C}^{\mathrm{O}} \mathrm{XV}^{\mathrm{o}}$. Pascha XIIII ${ }^{\circ}$. kalendas mai. Capta est ciuitas Maiorica et hoc de Martorel.

105 Tras "episcopus" otra mano ha añadido "in rota".

${ }^{106}$ Tras esta palabra, la segunda mano ha añadido "molleruça".

${ }^{107}$ Sobre la línea la segunda mano ha añadido "de" antes de "iherunde". 
(85) Anno $\mathrm{M}^{\mathrm{o}} \mathrm{C}^{\mathrm{o}} \mathrm{XVI}^{\mathrm{o}}$. Pascha $\mathrm{IIII}^{\mathrm{o}}$. nonas aprilis.

(86) Anno $\mathrm{M}^{\circ} \mathrm{C}^{\mathrm{O}} \mathrm{XVII}{ }^{\circ}$. Pascha VIII. kalendas aprilis. Obiit Bernardus comes Ceritanie.

(87) Anno $\mathrm{M}^{\circ} \mathrm{C}^{\mathrm{o}} \mathrm{XVIII}{ }^{\circ}$. Pascha XVIII. kalendas $\mathrm{m}^{\mathrm{a}} \mathrm{i}$. Cesaraugusta capta est ab Illefonso rege Aragonis.

(88) Anno $\mathrm{M}^{\mathrm{O}} \mathrm{C}^{\mathrm{o}} \mathrm{XVIIII^{ \circ }}$. Pascha $\mathrm{III}^{\circ}$. kalendas aprilis. Obiit Gelasius papa.

(89) Anno $\mathrm{M}^{\mathrm{o}} \mathrm{C}^{\mathrm{o}} \mathrm{XX}^{\mathrm{o}}$. Pascha XIIII. kalendas mai.

(90) Anno $\mathrm{M}^{0} \mathrm{C}^{\circ} \mathrm{XX}^{0} \mathrm{I}^{\circ}$. Pascha IIII. idus aprilis. Obiit Richardus archiepiscopus Narbone.

(91) Anno $\mathrm{M}^{0} \mathrm{C}^{\mathrm{o}} \mathrm{XX}^{\mathrm{o}} \mathrm{II}^{\circ}$. Pascha VII. kalendas aprilis. Obiit Oto episcopus Urgellis ${ }^{108}$.

(92) Anno $\mathrm{M}^{\mathrm{o}} \mathrm{C}^{\mathrm{o}} \mathrm{XX}^{\mathrm{o}} \mathrm{III}^{\mathrm{o}}$. Pascha XVII ${ }^{\mathrm{o}}$ kalendas $\mathrm{m}^{\mathrm{a}} \mathrm{i}$.

(93) Anno $\mathrm{M}^{\mathrm{O}} \mathrm{C}^{\mathrm{O}} \mathrm{XX}^{\mathrm{O}} \mathrm{IIII} \mathrm{O}^{\mathrm{O}}$. Pascha VIII idus aprilis.

(94) Anno $\mathrm{M}^{\circ} \mathrm{C}^{\mathrm{o}} \mathrm{XX}^{\circ} \mathrm{V}^{\circ}$. Pascha $\mathrm{IIII}^{\circ}$ kalendas aprilis.

(95) Anno $\mathrm{M}^{\circ} \mathrm{C}^{\mathrm{o}} \mathrm{XX}^{\mathrm{o}} \mathrm{VI}^{\circ}$. Pascha III ${ }^{\circ}$. idus aprilis. Obiit Raimundus episcopus Rote et Calixtus papa et Bernardus Raimundus comes Paliarensis.

(96) Anno $\mathrm{M}^{\mathrm{O}} \mathrm{C}^{\mathrm{O}} \mathrm{XX}^{\mathrm{O}} \mathrm{VII}^{\circ}$. Pascha $\mathrm{III}^{\mathrm{o}}$. nonas aprilis.

(97) Anno $\mathrm{M}^{\circ} \mathrm{C}^{\mathrm{O}} \mathrm{XX}^{\mathrm{o}} \mathrm{VIII}{ }^{\circ}$. Pascha $\mathrm{X}^{\circ}$. kalendas madii.

(98) Anno $M^{\circ} C^{0} X X^{0} V I I I I^{\circ}$. Pascha XVIII. kalendas $m^{a} i$.

(99) Anno $\mathrm{M}^{\mathrm{O}} \mathrm{C}^{\mathrm{O}} \mathrm{XXX}^{\mathrm{O}}$. Pascha $\mathrm{III}^{\circ}$. kalendas aprilis.

(100) Anno $\mathrm{M}^{\circ} \mathrm{C}^{\mathrm{o}} \mathrm{XXX}^{\mathrm{o}} \mathrm{I}^{\circ}$. Pascha XIII. kalendas mai. Raimundus comes Barchinone de Ripull.

(101) Anno $\mathrm{M}^{\circ} \mathrm{C}^{\mathrm{O}} \mathrm{XXX}^{\circ} \mathrm{II}^{\circ}$. Pascha IIII'. idus aprilis.

(102) Anno $\mathrm{M}^{\circ} \mathrm{C}^{\mathrm{O}} \mathrm{XXX}^{\mathrm{O}} \mathrm{III}^{\circ}$. Pascha VII. kalendas aprilis.

(103) Anno $\mathrm{M}^{\mathrm{O}} \mathrm{C}^{\mathrm{O}} \mathrm{XXX}^{\mathrm{o}} \mathrm{IIII}^{\mathrm{o}}$. Pascha XVII. kalendas mai. Rex Aragonensis Illefonsus $\mathrm{XXX}^{\circ}$. anno regni sui obiit. Arnaldus episcopus Osce obiit.

(104) Anno $\mathrm{M}^{\circ} \mathrm{C}^{\mathrm{O}} \mathrm{XXX}^{\mathrm{O}} \mathrm{V}^{\mathrm{o}}$. Pascha VII. idus aprilis.

(105) Anno $\mathrm{M}^{\mathrm{O}} \mathrm{C}^{\mathrm{O}} \mathrm{XXX}^{\mathrm{O}} \mathrm{VI}^{\mathrm{o}}$. Pascha XI. kalendas aprilis.

(106) Anno $\mathrm{M}^{\circ} \mathrm{C}^{0} \mathrm{XXX}^{\circ} \mathrm{VII}^{\circ}$. Pascha III. idus aprilis.

(107) Anno M C XXX.VIII. Pascha III ${ }^{\circ}$ nonas aprilis. Obiit Olegarius Tarragonensis archiepiscopus.

(108) Anno $\mathrm{M}^{\mathrm{O}} \mathrm{C}^{\mathrm{O}} \mathrm{XXX}^{\mathrm{o}} \mathrm{VIIII}^{\mathrm{o}}$. Pascha VIIII ${ }^{\mathrm{o}}$ kalendas mai.

(109) Anno $\mathrm{M}^{\mathrm{O}} \mathrm{C}^{\mathrm{O}} \mathrm{XXXX}^{\mathrm{O}}$. Pascha VIII ${ }^{\circ}$. idus aprilis.

(110) Anno $\mathrm{M}^{\circ} \mathrm{C}^{\mathrm{o}} \mathrm{XL}^{\mathrm{o}} \mathrm{I}^{\mathrm{o}}$. Pascha III. kalendas aprilis.

(111) Anno $\mathrm{M}^{\mathrm{o}} \mathrm{C}^{\mathrm{o}} \mathrm{XL}^{\mathrm{o}} \mathrm{II}^{\mathrm{o}}$. Pascha XVIII. kalendas $\mathrm{m}^{\mathrm{a}} \mathrm{i}$. Fuit captus Montson a comite Barchinone ${ }^{109}$.

(112) Anno $\mathrm{M}^{\circ} \mathrm{C}^{\mathrm{O}} \mathrm{XL}^{\mathrm{o}} \mathrm{III}{ }^{\circ}$. Pascha $\mathrm{II}^{\mathrm{o}}$. nonas aprilis.

(113) Anno $\mathrm{M}^{\mathrm{O}} \mathrm{C}^{\mathrm{O}} \mathrm{XL}^{\mathrm{o}} \mathrm{IIII}^{\mathrm{o}}$. Pascha VII. kalendas aprilis.

(114) Anno $\mathrm{M}^{\mathrm{o}} \mathrm{C}^{\mathrm{o}} \mathrm{XL}^{\mathrm{o}} \mathrm{V}^{\mathrm{o}}$. Pascha XVII. kalendas $\mathrm{m}^{\mathrm{a}} \mathrm{i}$.

(115) Anno $\mathrm{M}^{\mathrm{o}} \mathrm{C}^{\mathrm{O}} \mathrm{XL}^{\mathrm{o}} \mathrm{VI}^{\circ}$. Pascha $\mathrm{II}^{\circ}$ kalendas aprilis. Obiit Raimundus episcopus sedis Vici ${ }^{110}$.

(116) Anno $\mathrm{M}^{\mathrm{o}} \mathrm{C}^{\mathrm{o}} \mathrm{XL}^{\mathrm{o}} \mathrm{VII}^{\mathrm{o}}$. Pascha XII. kalendas $\mathrm{m}^{\mathrm{a}} \mathrm{i}$. Fuit capta Almaria a comite Barchinone.

(117) Anno $\mathrm{M}^{\circ} \mathrm{C}^{\mathrm{o}} \mathrm{XL}^{\circ}$ VIII ${ }^{\circ}$. Pascha III ${ }^{\circ}$. idus aprilis. Fuit capta Tortosa.

(118) Anno $\mathrm{M}^{\circ} \mathrm{C}^{\circ} \mathrm{XL}^{\circ} \mathrm{VIIII}^{\circ}$. Pascha III nonas aprilis. Fuit capta Ylerda et Fraga.

\footnotetext{
${ }^{108}$ Se diría que falta el signo de abreviación para indicar "Urgell(ens)is".

${ }^{109}$ No hay señal de abreviación, ni siquiera un punto, simplemente se lee "a comite bar". La noticia se lee en un recuadro añadido en el margen izquierdo, como si fuese una adición posterior.

${ }^{110}$ Esta noticia, como la precedente, se ha añadido en el margen izquierdo en letra más pequeña aprovechando el espacio en blanco.
} 
(119) Anno $\mathrm{M}^{\circ} \mathrm{C}^{\mathrm{o}} \mathrm{L}^{\mathrm{o}}$. Pascha XVI. kalendas mai.

(120) Anno $\mathrm{M}^{0} \mathrm{C}^{\mathrm{o}} \mathrm{L}^{\mathrm{o}} \mathrm{I}^{\mathrm{o}}$. Pascha $\mathrm{VI}^{\mathrm{o}}$. idus aprilis.

(121) Anno $\mathrm{M}^{\mathrm{o}} \mathrm{C}^{\mathrm{o}} \mathrm{L}^{\mathrm{o}} \mathrm{II}^{\mathrm{o}}$. Pascha $\mathrm{III}^{\circ}$ kalendas aprilis.

(122) Anno $M^{\circ} C^{0} L^{o} I_{I I}{ }^{\circ}$. Pascha XIII. kalendas $m^{a} i$. Fuit capta Siurana.

(123) Anno $M^{\circ} C^{0} L^{0} I I I I I^{\circ}$. Pascha II $I^{\circ}$. nonas aprilis.

(124) Anno $\mathrm{M}^{\mathrm{o}} \mathrm{C}^{\mathrm{o}} \mathrm{L}^{\mathrm{o}} \mathrm{V}^{\mathrm{o}}$. Pascha VI. kalendas aprilis.

(125) Anno $\mathrm{M}^{\mathrm{o}} \mathrm{C}^{\mathrm{o}} \mathrm{L}^{\mathrm{o}} \mathrm{VI}^{\mathrm{o}}$. Pascha XVII kalendas may.

(126) Anno $\mathrm{M}^{\circ} \mathrm{C}^{\mathrm{o}} \mathrm{L}^{\mathrm{o}} \mathrm{VII}^{\circ}$. Pascha $\mathrm{II}^{\mathrm{o}}$ kalendas aprilis.

(127) Anno $M^{0} C^{0} L^{0}$ VIIII. Pascha XII mai.

(128) Anno $\mathrm{M}^{\mathrm{O}} \mathrm{C}^{\mathrm{O}} \mathrm{L}^{\mathrm{O}}$ VIIIII ${ }^{\circ}$. Pascha II idus aprilis.

(129) Anno $\mathrm{M}^{\mathrm{O}} \mathrm{C}^{\mathrm{0}} \mathrm{LX}^{\mathrm{o}}$. Pascha XI kalendas aprilis.

(130) Anno $\mathrm{M}^{\mathrm{o}} \mathrm{C}^{\mathrm{o}} \mathrm{LX}^{\mathrm{o}} \mathrm{I}^{\mathrm{o}}$. Pascha XVI $\mathrm{I}^{\circ}$ kalendas may.

(131) Anno $\mathrm{M}^{\mathrm{o}} \mathrm{C}^{\mathrm{O}} \mathrm{LX}^{\mathrm{o}} \mathrm{II}^{\mathrm{O}}$. Pascha $\mathrm{VI}^{\mathrm{o}}$ idus aprilis. Obiit R. Bengarius comes Barchinone.

(132) Anno $\mathrm{M}^{\circ} \mathrm{C}^{\mathrm{O}} \mathrm{LX}^{\mathrm{O}} \mathrm{III} \mathrm{I}^{\circ}$. Pascha VIIII ${ }^{\circ}$ kalendas aprilis.

(133) Anno $\mathrm{M}^{\mathrm{O}} \mathrm{C}^{\mathrm{O}} \mathrm{LX}^{\mathrm{O}} \mathrm{IIII}^{\circ}$. Pascha $\mathrm{II}^{\circ}$. idus aprilis.

(134) Anno $\mathrm{M}^{\mathrm{O}} \mathrm{C}^{\mathrm{O}} \mathrm{LX}^{\mathrm{o}} \mathrm{V}^{\mathrm{o}}$. Pascha $\mathrm{II}^{\mathrm{o}}$ nonas aprilis.

(135) Anno $\mathrm{M}^{\mathrm{O}} \mathrm{C}^{\mathrm{O}} \mathrm{LX}^{\mathrm{O}} \mathrm{VI}^{\mathrm{o}}$. Pascha VIII kalendas mai.

(136) Anno $\mathrm{M}^{\circ} \mathrm{C}^{\mathrm{o}} \mathrm{LX}^{\mathrm{o}} \mathrm{VII}{ }^{\mathrm{o}}$. Pascha $\mathrm{V}^{\mathrm{o}}$ idus aprilis.

(137) Anno $\mathrm{M}^{\mathrm{O}} \mathrm{C}^{\mathrm{O}} \mathrm{LX}^{\mathrm{O}} \mathrm{VIIII}^{\mathrm{o}}$. Pascha II $\mathrm{II}^{\mathrm{o}}$ kalendas aprilis.

(138) Anno $\mathrm{M}^{0} \mathrm{C}^{\mathrm{o}} \mathrm{LX}^{\mathrm{o}}$ VIIIII ${ }^{\circ}$. Pascha XII kalendas $\mathrm{m}^{\mathrm{a}} \mathrm{i}$.

(139) Anno $\mathrm{M}^{\circ} \mathrm{C}^{0} \mathrm{LXX}^{\circ}$. Pascha nonas aprilis.

(140) Anno $M^{\circ} C^{\circ} \operatorname{LXX}^{\circ} I^{\circ}$. Pascha $V^{\circ}$ kalendas aprilis.

(141) Anno $\mathrm{M}^{\mathrm{o}} \mathrm{C}^{\mathrm{O}} \mathrm{LXX}^{\mathrm{O}} \mathrm{II}^{\mathrm{o}}$. Pascha XVI ${ }^{\circ}$ kalendas mai.

(142) Anno $\mathrm{M}^{\circ} \mathrm{C}^{\mathrm{O}} \mathrm{LXX}^{\mathrm{O}} \mathrm{III}^{\mathrm{O}}$. Pascha $\mathrm{VI}^{\circ}$ idus aprilis.

(143) Anno $\mathrm{M}^{\circ} \mathrm{C}^{\mathrm{O}} \mathrm{LXX}^{\mathrm{O}} \mathrm{IIII}^{\circ}$. Pascha VIIII. kalendas aprilis.

(144) Anno $\mathrm{M}^{\circ} \mathrm{C}^{\mathrm{O}} \mathrm{LXX}^{\circ} \mathrm{V}^{\mathrm{o}}$. Pascha idus aprilis.

(145) Anno $\mathrm{M}^{\mathrm{O}} \mathrm{C}^{\mathrm{O}} \mathrm{LXX}^{\mathrm{o}} \mathrm{VI}^{\mathrm{o}}$. Pascha $\mathrm{II}^{\mathrm{O}}$. nonas aprilis.

(146) Anno $\mathrm{M}^{\mathrm{o}} \mathrm{C}^{\mathrm{O}} \mathrm{LXX}^{\mathrm{O}} \mathrm{VII}^{\mathrm{o}}$. Pascha VIII. kalendas mai. Obiit Guillelmus episcopus.

(147) Anno $M^{\circ} C^{\circ} \mathrm{LXX}^{\circ}$ VIII ${ }^{\circ}$. Pascha $V^{\circ}$. idus aprilis.

(148) Anno $\mathrm{M}^{\circ} \mathrm{C}^{\mathrm{O}} \mathrm{LXX}^{\mathrm{O}} \mathrm{VIIII} \mathrm{I}^{\circ}$. Pascha kalendas aprilis.

(149) Anno $\mathrm{M}^{\circ} \mathrm{C}^{\mathrm{O}} \mathrm{LXXX}^{\circ}$. Pascha XII kalendas mai.

(150) Anno $M^{\circ} C^{0} \operatorname{LXXX}^{\circ} I^{0}$. Pascha nonas aprilis.

(151) Anno $\mathrm{M}^{\mathrm{O}} \mathrm{C}^{\mathrm{O}} \mathrm{LXXX}^{0} \mathrm{II}^{\mathrm{o}}$. Pascha $\mathrm{V}^{\mathrm{o}}$. kalendas aprilis.

(152) Anno $M^{0} C^{0} \operatorname{LXXX}^{0} \mathrm{III}^{\circ}$. Pascha $\mathrm{XV}^{\mathrm{o}}$. kalendas $\mathrm{m}^{\mathrm{a}} \mathrm{i}$.

(153) Anno $M^{\circ} \mathrm{C}^{\mathrm{O}} \mathrm{LXXX}^{\circ} \mathrm{IIII}^{\circ}$. Pascha kalendas aprilis.

(154) Anno $M^{\circ} C^{\circ} L_{X X X}{ }^{\circ} V^{\circ}$. Pascha $X^{\circ}$ kalendas mai.

(155) Anno $M^{\circ} C^{\circ} L_{X X X}{ }^{\circ} I^{\circ}$. Pascha idus aprilis.

(156) Anno $\mathrm{M}^{\circ} \mathrm{C}^{\mathrm{O}} \mathrm{LXXX}^{\mathrm{O}} \mathrm{VII}^{\circ}$. Pascha $\mathrm{IIII}^{\circ}$. kalendas aprilis.

(157) Anno $\mathrm{M}^{0} \mathrm{C}^{\mathrm{o}} \mathrm{LXXX}^{\mathrm{O}} \mathrm{VIII}^{\circ}$. Pascha XV $\mathrm{XV}^{\mathrm{o}}$ kalendas $\mathrm{m}^{\mathrm{a}} \mathrm{i}$.

(158) Anno $\mathrm{M}^{\mathrm{O}} \mathrm{C}^{\mathrm{O}} \mathrm{LXXX}^{\mathrm{O}} \mathrm{VIIII}^{\circ}$. Pascha $\mathrm{V}^{\mathrm{o}}$. idus aprilis.

(159) Anno $\mathrm{M}^{\mathrm{O}} \mathrm{C}^{\mathrm{O}} \mathrm{XC}^{\mathrm{O}}$. Pascha VIII ${ }^{\circ}$. kalendas aprilis.

(160) Anno $\mathrm{M}^{\circ} \mathrm{C}^{\mathrm{o}} \mathrm{XC}^{\mathrm{o}} \mathrm{I}^{\mathrm{o}}$. Pascha XVIII ${ }^{\circ}$ kalendas mai.

(161) Anno $\mathrm{M}^{\circ} \mathrm{C}^{\mathrm{O}} \mathrm{XC}^{\mathrm{O}} \mathrm{II}^{\mathrm{O}}$. Pascha nonas aprilis.

(162) Anno $\mathrm{M}^{\circ} \mathrm{C}^{\mathrm{O}} \mathrm{XC}^{\mathrm{o}} \mathrm{III}^{\circ}$. Pascha $\mathrm{V}^{\mathrm{o}}$ kalendas aprilis.

(163) Anno $\mathrm{M}^{\circ} \mathrm{C}^{\mathrm{o}} \mathrm{XC}^{\mathrm{o}} \mathrm{IIII}^{\circ}$. Pascha IIII $\mathrm{I}^{\circ}$. idus aprilis.

(164) Anno $\mathrm{M}^{0} \mathrm{C}^{\mathrm{o}} \mathrm{XC}^{\mathrm{o}} \mathrm{V}^{\mathrm{o}}$. Pascha IIII'. . nonas aprilis.

(165) Anno $\mathrm{M}^{\circ} \mathrm{C}^{\mathrm{o}} \mathrm{XC}^{\mathrm{O}} \mathrm{VI}^{\circ}$. Pascha $\mathrm{XI}^{\circ}$ kalendas mai. Obiit Illefonsus rex Aragonis.

(166) Anno $\mathrm{M}^{\circ} \mathrm{C}^{\mathrm{o}} \mathrm{XC}^{\mathrm{o}} \mathrm{VII}^{\mathrm{o}}$. Pascha VIII. idus aprilis.

(167) Anno $\mathrm{M}^{\mathrm{o}} \mathrm{C}^{\mathrm{O}} \mathrm{XC}^{\mathrm{O}} \mathrm{VIII} \mathrm{I}^{\circ}$. Pascha IIII $^{\circ}$. kalendas aprilis. 
(168) Anno $\mathrm{M}^{\mathrm{o}} \mathrm{C}^{\mathrm{o}} \mathrm{XC}^{\mathrm{o}} \mathrm{VIIII}{ }^{\circ}$. Pascha XIIII. kalendas $\mathrm{m}^{\mathrm{a}} \mathrm{i}$.

(169) Anno $\mathrm{M}^{\circ} \mathrm{CC}^{\circ}$. Pascha $\mathrm{V}^{\circ}$ idus aprilis.

(170) Anno $\mathrm{M}^{\mathrm{o}} \mathrm{CC}^{\mathrm{o}} \mathrm{I}^{\mathrm{o}}$. Pascha VIII ${ }^{\circ}$. kalendas aprilis.

(171) Anno $\mathrm{M}^{\circ} \mathrm{CC}^{\mathrm{o}} \mathrm{II}^{\circ}$. Pascha XVIII ${ }^{\circ}$. kalendas mai.

(172) Anno $\mathrm{M}^{\circ} \mathrm{CC}^{\mathrm{O}} \mathrm{III}^{\mathrm{O}}$. Pascha VIII $\mathrm{I}^{\circ}$. idus aprilis.

(173) Anno $\mathrm{M}^{\mathrm{O}} \mathrm{CC}^{\mathrm{o}} \mathrm{IIII}^{\mathrm{o}}$. Pascha VII ${ }^{\circ}$ kalendas mai.

(174) Anno $\mathrm{M}^{\circ} \mathrm{CC}^{\mathrm{o}} \mathrm{V}^{\mathrm{o}}$. Pascha IIII idus aprilis. Obiit Gombaldus episcopus

Rote $^{111}$.

(175) Anno $\mathrm{M}^{\mathrm{O}} \mathrm{CC}^{\mathrm{o}} \mathrm{VI}^{\mathrm{o}}$. Pascha nonas $\mathrm{IIII}^{\mathrm{o}}$ aprilis.

(176) (A)nno $\mathrm{M}^{\mathrm{o}} \mathrm{CCC}^{\mathrm{O}} \mathrm{LVIII}^{\mathrm{O}}$. (Pascha) XII. kalendas mai ${ }^{112}$.

Como he señalado más arriba, Coll Alentorn defendió en su día con buenos argumentos la existencia de dos partes bien diferenciadas en este cronicón: una primera sección llegaría hasta la segunda mitad del s. XI y habría sido elaborada en Santa María de Ripoll; a continuación, un manuscrito con esta obra habría llegado a Roda de Isàbena (en la comarca de Ribagorza en Aragón) y allí el cronicón habría sido continuado hasta $1205^{113}$. Coll Alentorn dedujo esta doble redacción del análisis de los contenidos del texto, pues no es sino a partir del último cuarto del s. XI cuando entran en el cronicón abundantes noticias sobre el reino de Aragón. Este investigador imaginó asimismo que esta composición habría llegado probablemente desde Ripoll a Roda de Isábena en tiempos del obispo Salomón de Roda (1068-1074/5), que antes de ser elevado a la cátedra episcopal de esta diócesis profesó como monje en Ripoll ${ }^{114}$. Dado que las ediciones precedentes de este texto no reproducen fielmente la versión manuscrita del códice Roda 29, donde la estructura analística del cronicón cambia a partir del año 1080, punto en el que el cronicón se transforma en unos anales pascuales, no había podido apreciarse que hay un claro hiato en el desarrollo del cronicón entre el año 1075 y el año 1080. En efecto, la entrada correspondiente al año 1075 (48) en la que se da cuenta de la muerte del obispo Guillermo Guifredo de Urgel, ocurrida el 24 de enero de 1075, es la última de la primera parte del texto (entradas 1-48). La segunda parte (entradas 49-176) comienza a partir del año 1080, momento en el que el Chronicon Rotense alterum avanza año por año, dando cuenta de la fecha de la pascua en todas y cada una de las entradas, mientras que sólo algunas de ellas incorporan noticias de carácter histórico, que se vuelven cada vez más raras conforme la obra va llegando al s. XIII. La primera noticia histórica de esta segunda parte del cronicón se encuentra recogida en la entrada del año 1082 (51) (f. 205rb), donde se da cuenta del asesinato del conde de Barcelona Ramón Berenguer II. A su vez, la última noticia de interés histórico se lee en la entrada del año 1205 (174) (f. 207rb) y hace referencia a la muerte del obispo de Lérida Gombaldo de Camporrells, acaecida el 21 de abril de 1205 . Pero los anales pascuales continúan en este códice hasta el f. 208vb, donde concluyen en el año 1358 (176).

${ }^{111}$ Gombaldo de Camporrells, obispo de Lérida (1192-1205), vid. P. SÁNCHEZ, Lérida, Diócesis de, DHEE, vol. 2, pp. 1291-1295 (en la p. 1294); Ramiro VIOLA GONZÁLEZ, Gombau de Camporrells, DHEC, vol. 2, p. 295.

${ }^{112}$ Sigue la tabla pascual hasta 1358, concluyendo en el f. 208vb, donde finaliza así, con una sola entrada, que es la que aquí transcribo. En ella se han dejado en blanco los huecos para escribir en rojo la A de "Anno" y la abreviatura $\mathrm{P}^{\mathrm{a}}$ de "Pascha", pero no se han llegado a escribir estas letras.

${ }^{113}$ M. COLL Alentorn, La historiografia de Catalunya, pp. 155-157.

${ }^{114}$ Sobre Salomón de Roda, vid. M. C. DÍAZ Y DÍAZ, Salomón, DHEE, vol. 4, p. 2155; Jordi MASCARElla Rovira, Salomó, DHEC, vol. 3, pp. 331-332; y Francisco Castillón CorTada, Episcopologio de Roda de Isábena, "Aragonia Sacra”, 16-17 (2001-2003), pp. 51-58, en las pp. 53-54. 
Es significativo que la fecha en que concluye la primera sección de estos anales, la parte relacionada con Ripoll, coincida con la muerte de Salomón de Roda. Se diría, en efecto, que fue justamente después de este suceso cuando cambió la perspectiva de esta compilación analística. Por ello, resulta verosímil atribuir a Salomón de Roda, o a su entorno, la versión final de la parte ripollesa del Chronicon Rotense alterum.

\section{LA ANALÍSTICA LATINA CASTELLANO-LEONESA}

\subsection{Los Annales Castellani Recentiores (Díaz 904)}

Los siguientes testimonios de los anales de los mártires analizados en este trabajo me llevan ahora a los dominios castellano-leoneses. En esta zona se elaboró, en efecto, en torno al año 1111 la primera de las cuatro piezas que constituyen el texto que Gómez-Moreno definió como Anales Castellanos Segundos ${ }^{115}$. Pues bien, en estos nuevos anales las dos fuentes principales de las primeras entradas son los Annales Castellani Antiquiores (Díaz 574), de hacia 946, y unos anales sobre el nacimiento y la pasión de Cristo que podrían ser tanto los del códice de Azagra como los del códice de Roda, aunque realmente, como veremos, son las eras del códice de Azagra las que parecen haber ejercido una cierta influencia en la analística latina castellano-leone$\mathrm{sa}^{116}$. En cualquier caso, es significativo que los testimonios conocidos de la tradición indirecta de los anales martiriales de los códices de Azagra y de Roda en territorio castellano-leonés sean posteriores a los testimonios detectados en la región catalana. Esta cronología ofrecida por la tradición indirecta es un dato de interés que pone en relación, una vez más, el origen de estos anales antes con el noreste peninsular que con el noroeste.

Éstas son las dos primeras entradas de los Annales Castellani Recentiores ${ }^{117}$ :

I,1. In era .XXX ${ }^{\mathrm{a}}$ VIII ${ }^{\mathrm{a}}$. Ihesus Xpistus filius Dei uiui in Ierusalem Iudee de uirgine Maria natus est sub Herode rege ${ }^{118}$.

I,2. In era .LXVIIII. Ihesus Xpistus ad passionem uenit anno Tyberii .XIIII. ${ }^{119}$

115 Sobre esta obra y los Annales Castellani Antiquiores, citados más adelante, vid. Jose Carlos MARTín, Los Annales Castellani Antiquiores y Annales Castellani Recentiores: edición y traducción anotada, "Territorio, sociedad y poder", 4 (2009), pp. 203-226, e ID., Los comienzos de las letras latinas en Castilla y León: de los Anales Castellanos Primeros a los Segundos, in Modelos latinos en la Castilla medieval, (M. CASTILlo LluCH, M. LÓPEZ IZQUIERDO, eds.), Frankfurt-Madrid, 2010 (Medievalia hispanica, 14), pp. 331-346.

${ }^{116}$ Por su parte, Díaz y Díaz puso en relación estas primeras entradas de los Annales Castellani Recentiores con una Notitia martyrum, sin especificar a qué texto se refería en concreto, quizás a la Notitia martyrum (Díaz 572 ), y señaló que probablemente los Annales Castellani Antiquiores se presentan mutilados por el comienzo, puesto que no incluyen esas entradas, aunque lo más probable es que la fuente, sean, como señalo, las eras del códice de Azagra, que por la época en que se redactaron los A. Castellani Antiquiores no habrían sido conocidas por el autor de estos anales. Vid. M. C. DíAZ Y DíAZ, La historiografía hispana desde la invasión árabe hasta el año 1000, in De Isidoro al siglo XI. Ocho estudios sobre la vida literaria peninsular, Barcelona, 1976, pp. 203-234 (= La storiografia altomedievale, vol. 1, Spoleto, 1970 [Settimane di Studio del Centro Italiano di Studi sull'Alto Medioevo, 17], pp. 313-343), pp. 230-231.

${ }^{117}$ Cito por J. C. MARTín, Los Annales Castellani Antiquiores y Annales Castellani Recentiores, pp. 215-218.

${ }^{118}$ Posible fuente: Eras in quo martires passi sunt 1, o Annales martyrum codicis Rotensis 1.

${ }^{119}$ Posible fuente: Eras in quo martires passi sunt 4, o Annales martyrum codicis Rotensis 4. 


\subsection{Los Annales Onienses (Chronicon paruum Ambrosianum dictum) (Díaz-)}

Dentro de Castilla puede citarse también una obrita que, en virtud de su origen más probable, denominaré Annales Onienses. Estos anales fueron editados por Muratori en 1726 y reeditados a partir de esta edición por Flórez en 1767 en la España Sagrada bajo el título de Chronicon paruum Ambrosianum, por transmitirse este texto en un códice de la Biblioteca Ambrosiana de Milán ${ }^{120}$.

Aunque Muratori no da noticia de la signatura del códice que emplea en su edición, no es difícil darse cuenta de que se trata de Milano, Biblioteca Ambrosiana, F 105 sup., un volumen de finales del s. XII o, a lo sumo, comienzos del XIII ejecutado verosímilmente en San Salvador de Oña en Burgos ${ }^{121}$.

Las dos ediciones señaladas son muy deficientes, por lo que ofrezco a continuación mi propia edición de estos Annales Onienses, basada en el único manuscrito conocido, ya citado, f. 22v:

(1) Era XXX ${ }^{\mathrm{a}} \cdot \mathrm{VIII}{ }^{\mathrm{a}}$. Ihesus Xps in Betleem natus est.

(2) Era XL ${ }^{\mathrm{a}} \cdot \mathrm{VII}$. . Herodes rex occidit infantes.

(3) Era LX $X^{\mathrm{a}} \mathrm{V}^{\mathrm{a}}$. Iohannes baptista ab Herode decollatus est.

(4) Era LXa. VIIII ${ }^{a}$. Dominus ad passionem uenit.

(5) Era $C^{\mathrm{a}}$. VIII ${ }^{\mathrm{a}}$. Petrus et Paulus passi sunt.

(6) Era $\mathrm{C}^{\mathrm{a}} \cdot \mathrm{XXX}^{\mathrm{a}}$.VIII' ${ }^{\mathrm{a}}$. Iohannes euangelista assumptus est.

(7) Era $C^{a} \cdot X^{a} \cdot V I^{a}$. Filipus et Symon passi sunt.

(8) Era

(9) Era

(10) Era

(11) Era

(12) Era

(13) Era

(14) Era $C C^{a} \cdot L X^{a}$. passi sunt Facundus et Primitiuus.

(15) Era CC ${ }^{\mathrm{a}} \cdot \mathrm{LX}^{\mathrm{a}}$.VII ${ }^{\mathrm{a}}$. passa est sancta Caecilia.

(16) Era

(17) Era

(18) Era CCC ${ }^{\mathrm{a}} \cdot \mathrm{LXXX}^{\mathrm{a}} \cdot \mathrm{II}^{\mathrm{a}}$. obiit sanctus Martinus.

(19) Era $D C^{a} \cdot \mathrm{LVI}^{\mathrm{a}}$. prophetauit Mahomat.

(20) Era $\mathrm{DC}^{\mathrm{a}} \cdot \mathrm{XL}^{\mathrm{a}}$. obiit Leander episcopus.

(21) Era DC $C^{\mathrm{a}} \cdot \mathrm{XL}^{\mathrm{a}} \cdot \mathrm{II}^{\mathrm{a}}$. obiit sanctus Emilianus.

(22) Era DC ${ }^{a} \cdot$ LXX $^{\mathrm{a}}$.IIII ${ }^{\mathrm{a}}$. obiit Isydorus episcopus.

(23) Era

(24) Era DCCCC ${ }^{\mathrm{a}}$.LX.IIII ${ }^{\mathrm{a}}$. passus est beatus Pelagius.

(25) Era

(26) $\mathrm{Era} \mathrm{M}^{\mathrm{a}} \cdot \mathrm{CC}^{\mathrm{a}} \cdot \mathrm{VIIIII}^{\mathrm{a}}$. passus est sanctus Thomas Cantuariensis.

${ }^{120}$ Las dos ediciones son Ludovico A. MURATORI, Rerum Italicarum scriptores, 25 vols., Mediolani, 1723-1751 (reimp. Bologna, 1981), vol. 2,2, pp. 1024-25; y E. FLóREZ, España Sagrada, vol. 23, Madrid, 1767, p. 305 (1799², p. 306).

${ }^{121}$ Esta es la tesis, al menos, de dos grandes especialistas que han estudiado este manuscrito: Germain MoRIN, Rainaud l'ermite et Ives de Chartres: un épisode de la crise du cénobitisme au XI ${ }^{e}$-XII siècle, "Revue Bénédictine", 40 (1928), pp. 99-115, en las pp. 100-101 (gracias a este trabajo, n. 4 de la p. 100, descubrí el folio en el que se transmiten estos anales poco conocidos) y B. de GAIFFIER, Un calendrier franco-hispanique. La tesis de su datación y origen no se establece a partir de los anales que aquí estudio, sino del calendario que ocupa los primeros folios del códice, editado por Gaiffier. 

(27) Era
(28) Era
(29) Era $M^{\mathrm{a}} \cdot \mathrm{LXXXX}^{\mathrm{a}}$. obiit beatus Enneco ${ }^{122}$.
(30) Era $\mathrm{M}^{\mathrm{a}} \cdot \mathrm{C}^{\mathrm{a}} \cdot \mathrm{XI}^{\mathrm{a}}$. obiit sanctus Dominicus ${ }^{123}$.
(31) Era $\mathrm{M}^{\mathrm{a}} \cdot \mathrm{CC}^{\mathrm{a}} \cdot \mathrm{I}^{\mathrm{a}}$. obiit beatus Iohannes de Urteca.

La última entrada de estos anales (31) versa sobre la muerte de san Juan de Ortega, acaecida en $1163^{124}$. Unas pocas líneas antes, no obstante, se encuentra otra entrada que da cuenta del fallecimiento de Tomás Becket (26), asesinado en diciembre de 1170 y canonizado en 1173. Morin, que reproduce las últimas líneas de estos anales, señala que esta entrada ha sido añadida por una mano posterior, al igual que la entrada del calendario que precede a estos anales en que se honra el natalicio de Tomás Becket ${ }^{125}$. Gaiffier en su estudio del calendario, rechaza que la inclusión de la noticia sobre Tomás Becket en el calendario se deba a otra mano ${ }^{126}$, y en la reproducción que he podido consultar de estos anales, tampoco parece que la referencia a este santo se deba a una mano más tardía. En consecuencia, la canonización de Tomás Becket en 1173 sería el terminus post quem de redacción del códice, en general, y de estos anales, en particular.

\subsection{Los Annales Burgenses (Díaz 1192) y los Annales Compostellani (Díaz 1290)}

Bautista considera que estos Annales Onienses dependerían de los denominados Annales Compostellani (Díaz 1290), que datan de 1248 y procederían quizás de Santo Domingo de la Calzada ${ }^{127}$. En su opinión, dentro de los Annales Compos-

\footnotetext{
${ }^{122}$ Se trata del abad Íñigo de San Salvador de Oña (OSB) $(\dagger 1068)$, monasterio situado en la provincia de Burgos. No tuvo culto litúrgico hasta 1163. Vid. Justo FERnÁnDEZ AlONSO, Enecone, in Bibliotheca sanctorum, 12 vols., Roma, 1961-1969, vol. 4, col. 1207; T. MORAL, Íñigo, DHEE, vol. 2, pp. 1206-07; José Javier RoDRÍGUEZ VELASCO, Íñigo, in Diccionario de los santos, 2 vols., (C. LEONARDI, A. RICCARDI, G. ZARRIM, dirs.), Madrid, 2000, vol. 1, pp. 1092-93. Esta entrada debe ponerse en relación evidente con el calendario que precede en el manuscrito (ed. de B. de GAIFFIER, Un calendrier franco-hispanique), donde se recoge la translatio de este mismo abad, en referencia, sin duda, a la segunda traslación de sus restos en 1165, vid. Enrique HERRERA Y ORIA, Autenticidad de las reliquias de san Íñigo, abad de Oña, "Revista de Archivos, Bibliotecas y Museos", 38 (1918), pp. 360-381, en las pp. 362-363, y resumen en la p. 381, la primera traslación de las reliquias de este santo tuvo lugar en 1125, y la segunda, probablemente a la que se refiere aquí el calendario, en 1165, con motivo de su canonización (no se indica, sin embargo, en este trabajo en qué día del año se produjo la canonización y segunda traslación de los restos de san Íñigo, que en el calendario citado se fecha un 28 de marzo).

${ }^{123}$ Santo Domingo de Silos (OSB) $(† 1073)$.

${ }^{124}$ Fue éste un discípulo, según la tradición, de santo Domingo de la Calzada. Construyó un pequeño santuario consagrado a san Nicolás en Ortega, un paraje solitario junto al camino de Santiago, hoy San Juan de Ortega, en Burgos. Vid. J. FernándeZ Alonso, Giovanni di Ortega, in Bibliotheca sanctorum, vol. 6, cols. 858-859; J. J. RODRÍGUEZ VELASCO, Juan de Ortega, in Diccionario de los santos, vol. 2, pp. 1337-39.

${ }^{125}$ G. Morin, Rainaud l'ermite, n. 4 de la p. 100.

${ }^{126}$ B. de GAIFFIER, Un calendrier franco-hispanique, p. 282.

${ }^{127}$ F. BAUTISTA, Breve historiografía, pp. 152-153. Esta tesis remonta a Manuel GóMEZ-MORENO, Anales Castellanos, in Discursos leídos ante la Real Academia de la Historia en la recepción de D. Manuel Gómez-Moreno Martínez el día 27 de mayo de 1917, Madrid, 1917, pp. 5-30, en la p. 21; y aparece recogida por Juan GIL, La historiografía, in La cultura del románico: siglos XI al XIII. Letras, religiosidad, artes, ciencia y vida, (F. LÓPEZ ESTRADA, coord.), Madrid, 1995 (Historia de España Menéndez Pidal, 11), pp. 1-109, en la p. 72. Sobre los Annales Compostellani, vid. asimismo Benito
} 
tellani pueden observarse diversas redacciones anteriores a la última conservada, de 1248, por lo que la datación tardía de la versión final de este texto no sería óbice para postular la dependencia de éstos por parte de los Annales Onienses. Sin duda, estos dos anales presentan estrechas semejanzas entre ellos al tiempo que con unos terceros anales, los denominados Annales Burgenses compuestos hacia 1212 en territorio burgalés (Díaz 1192) ${ }^{128}$. Si se comparan las entradas iniciales de estas tres compilaciones, hasta la muerte de Isidoro de Sevilla, se observa con claridad que son prácticamente idénticas. Pero esto no es más que una impresión general y todas y cada de las entradas deben analizarse con mucho cuidado para determinar si, en efecto, existe algún tipo de relación de dependencia entre estos textos.

Reproduzco a continuación las primeras entradas de los Annales Burgenses y de los Annales Compostelani, que numero para mayor comodidad de cita:

a) Annales Burgenses ${ }^{129}$ :

(1) Era XXXVIII ${ }^{\mathrm{a}}$ Ihesus Christus natus est.

(2) Era XLII ${ }^{\mathrm{a}}$ Herodes rex occidit infantes.

(3) Era LXV'a Iohannes Baptista ab Herode decollatus est.

(4) Era LXXI ${ }^{\mathrm{a}}$ Dominus Ihesus Christus ad passionem uenit.

(5) Era CVIII ${ }^{\mathrm{a}}$ Petrus et Paulus passi sunt.

(6) Era CCCCLXXXII obiit sanctus Martinus.

(7) Era CXXX Iohannes Euangelista assumptus est.

(8) Era CXLVI ${ }^{\mathrm{a}}$ Philipus et Simon passi sunt.

(9) Era DCXL ${ }^{a}$ obiit Leander episcopus.

(10) Era DCXII ${ }^{\mathrm{a}}$ obiit beatus Emilianus.

(11) Era DCLXXIIIII $I^{\mathrm{a}}$ obiit Ysidorus episcopus.

(12) Era DCCXLIX ${ }^{\mathrm{a}}$ intrauerunt sarraceni Ispanias tempore regis toletani

Roderici.

b) Annales Compostelani ${ }^{130}$ :

(1) Sub .i. era XXXVIII Jhesus Christus in Bethelem natus est.

(2) Era XLII Herodes rex occidit infantes.

(3) Era LXV Joannes Baptista decollatus est.

(4) Era XLVIII ${ }^{\circ}$ Dominus ad passionem venit.

(5) Era CVIII ${ }^{\circ}$ Petrus et Paulus passi sunt.

(6) Era CXXXVIII Johannes Euangelista assumptus est.

(7) Era CXLVI Philippus passus est.

(8) Era CCLX Facundus et Primitiuus passi sunt.

(9) Era CCLXVII passa est sancta Cecilia.

(10) Era DCCCII obiit beatus Martinus.

(11) Era DCXLII obiit beatus Aemilianus.

(12) Era DCLVI Mahomat pseudo propheta prophetauit tempore Sisebuti regis Toletani.

SÁNCHEZ AlONSO, Historia de la historiografía española, vol. 1. Hasta la publicación de la Crónica de Ocampo (...-1543), Madrid, 1947, pp. 146-147; y RFHMA, vol. 2, p. 266: "Anales Compostelanos".

${ }^{128}$ Vid. SÁNCHEZ AlONSO, Historia de la historiografía española, vol. 1, pp. 146-147; RFHMA, vol. 3, p. 303: "Chronicon Burgense"; Gonzalo MARTínEZ DíEZ, Tres anales burgaleses medievales, "Boletín de la Institución Fernán González", 83 (2004), pp. 227-263, en las pp. 230-232.

${ }^{129}$ Cito por G. MARTíNeZ DíEZ, Tres anales burgaleses, pp. 233-235.

${ }^{130}$ Cito por José M ${ }^{a}$. FERnÁNDEZ CATÓN, El llamado Tumbo Colorado y otros códices de la Iglesia Compostelana. Ensayo de reconstrucción, León, 1990, pp. 251-258. 
(13) Era DCLXXIIII obiit Isidorus episcopus, II nonas aprilis.

(14) Era DCCXLXIX intrauerunt Hispaniam sarraceni tempore Roderici regis Toletani.

Así, en la entrada n. 7 (era 146) de los A. Onienses se lee "Filipus et Symon passi sunt", igual que en los A. Burgenses (8), mientras que en los A. Compostellani se menciona solamente a Felipe (7). Mucho más significativo es el testimonio de la entrada dedicada a la muerte de Leandro de Sevilla, compartida por los anales de Oña (20) y Burgos (9), pero que no se incluye en los Compostelanos, lo que descarta que sean éstos la fuente de cualquiera de los otros dos. A su vez, las entradas sobre Facundo y Primitivo, Cecilia y Mahoma se pueden leer tanto en los anales de Oña (14-15, 19) como en los Compostelanos $(8-9,12)$, pero no en los de Burgos. Mi conclusión es que los tres anales remontan en su inicio a una misma fuente que puede reconstruirse a grandes rasgos hasta la muerte de Isidoro de Sevilla a partir del testimonio común de los tres opúsculos y es reproducida, sobre todo, por los Annales Compostellani. Es muy probable, no obstante, que esta fuente común continuase más allá de la fecha señalada (el óbito de Isidoro de Sevilla), tal y como se deduce de la comparación entre los A. Burgenses y los A. Compostellani ${ }^{131}$.

Si analizamos ahora si esta fuente común de los A. Onienses, los Burgenses y los Compostellani depende de las eras del códice de Azagra o de los anales del códice de Roda, los datos más significativos son los siguientes: por un lado, los tres anales castellanos citados incluyen una entrada dedicada a los apóstoles Felipe y Simón (A. Onienses, n. ${ }^{\circ} 7 ;$ A. Burgenses, n. $^{\circ} 8$ ), reducida a Felipe en el caso de los Compostelanos (7), cuando sólo las eras de Azagra incluyen una entrada sobre Simón (7); por otro lado, la pasión de san Pedro y san Pablo se fija en la era 108 en los tres anales (en todos ellos es la entrada $n^{\circ} 5$ ), coincidiendo en ello con las eras de Azagra (5) y apartándose de la datación de los anales de Roda, donde figura la era 109 (5); y finalmente, no puede citarse un solo pasaje propio de los anales del códice de Roda presente en estos anales castellanos. Se diría, en consecuencia, que son las eras del códice de Azagra probablemente la fuente de los anales que han sido utilizados en la elaboración de la fuente común que está en el origen de las primeras entradas de las tres compilaciones que acabamos de ver.

\section{LA ANALÍSTICA LATINA PORTUGUESA}

El repaso de la posteridad literaria de los anales martiriales de los códices de Azagra y de Roda me lleva a examinar dos textos analísticos portugueses conocidos como Chronicon Conimbricense mixtum (Díaz -), compilado hacia 1190 en Santa Cruz de Coímbra y del que aquí interesa la quinta parte, y Annales Lamecenses (Díaz 1001), que pueden fecharse en 1262 y situarse, como su propio nombre indica, en Lamego. Antes de analizar el denominado Chronicon Conimbricense mixtum, baste decir a propósito de los Annales Lamecenses que, de acuerdo con el estudio fundamental de David sobre todos estos textos, el cronicón de Santa Cruz de Coímbra está en la base de los anales de Lamego, de modo que dejaré estos últimos a un lado, puesto que no dependen de forma directa de los anales objeto de este estudio ${ }^{132}$.

${ }^{131}$ La estrecha relación existente entre estos tres anales fue puesta de manifiesto en su momento por B. SÁNCHEZ AlONSO, Historia de la historiografía española, vol. 1, p. 146.

${ }^{132}$ Vid. P. DAVID, Études historiques, pp. 257-340 ("Annales Portugalenses veteres"), esp. pp. 265-274 (sobre el Chronicon Conimbricense mixtum) y pp. 274-275 (sobre los Annales La- 
Como he hecho en todo momento a lo largo de este trabajo, ofrezco, en primer lugar, el texto del Chronicon Conimbricense mixtum. Pars $V^{133}$ :

(1) Era XXX ${ }^{\mathrm{a}}$ VIII ${ }^{\mathrm{a}}$. Natus fuit Dominus noster Iezus ${ }^{134}$ Christus.

(2) Era LX ${ }^{a}$ VIII ${ }^{a}$. Decollatus fuit sanctus Iohanes.

(3) Era LX ${ }^{a} I^{a}$. Sanctus Iacobus apostolus.

(4) Era C ${ }^{\mathrm{a}}$ VIII ${ }^{\mathrm{a}}$. Sanctus Petrus apostolus.

(5) Era $C^{a}{ }^{a} L^{a}{ }^{a}$ VIII'. Sanctus Ciprianus.

(6) Era $C^{2} C^{\mathrm{a}} \mathrm{XX}^{\mathrm{a}}$ VIII ${ }^{\mathrm{a}}$. Sanctus Iulianus et Basillisse.

(7) Era $\mathrm{CCCC}^{\mathrm{a}} \mathrm{XL}^{\mathrm{a}}$ VII. Sanctus Martinus.

(8) Ab diluuio usque ad Abraham DCCCC XLII anni.

(9) Ab Abraham usque ad exitum filiorum Israel ex Exipto ${ }^{135}$ quingenti quinque.

(10) Ab egressu filiorum Israel ex Egipto usque ad Dauid anni quadringenti XL V $\mathrm{V}^{\mathrm{a}}$.

(11) Ab Dauid usque transmigrationem CCCC LXXX III anni.

(12) Transmigratione Babilonis usque ad natiuitatem Christi D XX VI. anni.

(13) Collinguntur omnes anni ab Adam usque Christum quinque milia centum nonaginta nouem.

(14) XI. kalendarum februarii, passio sancti Vincenti. Era $\mathrm{CCC}^{\mathrm{a}} \cdot \mathrm{X}^{\mathrm{a}} \cdot \mathrm{VI}^{\mathrm{a}}$.

En esta sección del cronicón de Coímbra, la entrada más significativa es la que se refiere al apóstol Santiago, sin duda, Santiago el Mayor, cuya muerte se fecha en la era 61 (3). Esta noticia no se encuentra en las eras de Azagra, mientras que sí puede leerse en los anales del códice de Roda (4), datada en la era 72, un número muy parecido al 61, y más si tenemos en cuenta que en el citado códice la entrada aparece asociada a la de la pasión de Cristo en la era 71, por lo que una confusión entre 61 y 71/72 se explicaría fácilmente. Ni esta noticia ni las referidas a Cipriano (5) y a Julián y Basilisa (6) se encuentran recogidas en ninguno de los tres anales castellanos citados anteriormente. Por el contrario, tanto Cipriano de Cartago como Julián de Antince son honrados tanto en las eras de Azagra $(14,18)$ como en los anales del códice de Roda $(13,16)$. De estas dos entradas, encuentro especialmente significativa la referida a Cipriano, fechada en la era 298 en el Chronicon Conimbricense mixtum, lo que la pone en relación con los anales del códice de Roda, en los que se fecha en la era 299 (13), mientras que en las eras de Azagra aparece datada en la era 248 (14). Esta variante viene a confirmar que con toda probabilidad fue un texto semejante a los Annales martyrum codicis Rotensis el

\footnotetext{
mecenses). Pueden consultarse también RFHMA, vol. 3, p. 316: "Chronicon Conimbricense" y p. 363: "Chronicon Lamecense"; y F. BAUTISTA, Breve historiografía, pp. 173-177.

${ }^{133}$ Cito por Alexandre Herculano, Portugaliae Monumenta Historica a saeculo octavo post Christum usque ad quintundecimum, vol. 1. Scriptores, Lisboa, 1856 (reimp. Liechtenstein, 1967), dentro del Chronicon Conimbricense o Livro da Noa, pp. 2-5, $\mathrm{n}^{\circ} 5$ (pp. 2-3), en especial, las entradas que aquí numero 1-7 (p. 2). Los Annales Lamecenses pueden leerse en esta misma edición, en las pp. 19-20, sus primeras entradas son las siguientes: “(1) Omnes anni ab Adam usque ad Christum sunt quinque milia C XC IX. (2) Natus fuit Christus in Bethleem Iude. Era XXX ${ }^{\mathrm{a}}$ VIII. (3) Decollatus fuit sanctus Iohanes Babtista. Era LX ${ }^{\mathrm{a}}$ VIII. (4) Sanctus Iacobus apostolus. Era LX ${ }^{\mathrm{a}}$ I. (5) Sanctus Petrus apostolus. Era C VIII ${ }^{\mathrm{a}}$. (6) Sanctus Ciprianus. Era CC ${ }^{\mathrm{a}}$ nonagesima nona. (7) Sancti Iulianus et Basilissa. Era CCC $^{\mathrm{a}}$ XX VII ${ }^{\mathrm{a}}$. (8) Sanctus Martinus. Era CCCC $^{\mathrm{a}}$ XVII $^{\mathrm{a}}$. (9) In Portugalia natus fuit Rex Alfonsus filius regine Tarasie et comitis Enrichi. Era $\left(\mathrm{M}^{\mathrm{a}} \mathrm{C}^{\mathrm{a}}\right) \mathrm{XXXX}$ VIII ${ }^{\mathrm{a}}$....".

${ }^{134}$ Así en la edición de Herculano.

${ }^{135}$ Así en la edición de Herculano.
} 
empleado en la elaboración del Chronicon Conimbricense mixtum. A esta observación se sumaría un segundo indicio derivado de otra de las fuentes utilizadas por el anónimo compilador portugués: la denominada Crónica de Albelda (Díaz 514), una obra transmitida igualmente por el códice de Roda y ausente del ejemplar de Azagra.

\section{CONCLUSIÓN}

A modo de resumen, creo que las Eras in quo martires passi sunt transmitidas por el códice de Azagra ponen de manifiesto una cierta influencia del culto litúrgico francés. Su fecha de redacción es, por el momento, totalmente incierta, pudiendo fecharse entre comienzos del s. V y comienzos del X, en que esta obra era conocida en la Península Ibérica, como prueban los últimos folios del códice de Azagra, añadidos en los dominios cristianos del norte a un manuscrito de origen cordobés. En cualquier caso, tiendo a ver en ella una pieza más cercana a los ss. IX-X que al V.

Por esas fechas probablemente, ya en territorio hispano, entre el s. IX y mediados del s. X, esta obrita fue revisada haciendo uso, al menos, de la Crónica de Próspero de Aquitania y ampliada con diversas noticias de mártires que incluían varios santos de origen hispano o enterrados supuestamente en la Península Ibérica, como Santiago el Mayor, Vicente, Sabina y Cristena, Cucufate y Eulalia de Barcelona. El testimonio más antiguo de ello es proporcionado por la tradición indirecta en la primera parte del denominado Chronicon alterum Riuipullense, de hacia 984 y originario verosímilmente de San Miguel de Cuixá, o quizás de Ripoll. Poco después, a comienzos del XI, esta recensión larga fue copiada en Nájera en el denominado códice de Roda, precedida de un catálogo de perseguidores fijado a partir de la Crónica de Eusebio-Jerónimo, sin que pueda determinarse con total seguridad si formaba parte originalmente de esta segunda redacción, lo que encuentro más probable, o se debe al responsable de la ejecución de este manuscrito en concreto.

Probablemente, el mismo ejemplar de los anales de los mártires utilizados en la elaboración del Chronicon alterum Riuipullense, o uno muy parecido, fue utilizado en la composición de la primera sección del Chronicon Rotense alterum, una parte que finaliza en 1075 y es originaria de Santa María Ripoll. Todo indica que hay que atribuir a Salomón de Roda o a su círculo esta reunión de materiales que concluyen en 1075.

Mientras tanto, uno o varios códices que contenían las eras de los mártires del códice de Azagra comenzaban a circular por territorio castellano-leonés. Uno de estos ejemplares parece haber sido utilizado en la elaboración de la primera de las piezas que conforman los denominados Annales Castellani Recentiores, pieza que puede fecharse hacia 1111. Este mismo manuscrito o uno muy parecido habría servido igualmente a un historiador castellano para redactar unos anales latinos que parecen hoy perdidos, pero que pueden reconstruirse parcialmente a partir del testimonio de los Annales Onienses del códice F 105 sup. de la Biblioteca Ambrosiana de Milán, redactados verosímilmente en San Salvador de Oña hacia 1173, de los Annales Burgenses de hacia 1212 y de los Annales Compostellani de hacia 1248, estos últimos quizás de Santo Domingo de la Calzada. Estos anales se extendían al menos hasta el óbito de Isidoro de Sevilla. Probablemente, una de sus fuentes fueron las eras de los mártires del códice de Azagra. Los Annales Burgenses y Compostellani comparten además otras entradas, unas veces idénticas, otras muy parecidas, en las que se detectan otras fuentes, como los Annales Castellani Antiquiores de hacia 946, de los que se habrían tomado varias noticias desde la llegada de los árabes a Hispania hasta la repoblación de Burgos por parte del conde castellano Diego Rodríguez (873-885). A juicio de Martínez Díez, los Annales Compostellani y los Burgenses comparten una misma fuente hasta el primer 
tercio del s. XI y sólo comienzan a divergir a partir de $1035^{136}$. No obstante, esta fuente común podría llegar, al menos, hasta la muerte de santo Domingo de Silos en 1073, noticia compartida por los Annales Onienses (30) y Burgenses (era 1111), una impresión que se refuerza por el hecho de que estas dos mismas obras comparten igualmente una noticia mucho más rara como es la muerte del abad Ínigo de Oña en 1068 (n. ${ }^{\circ} 29$ de los Onienses y era 1095 de los Burgenses). Estas entradas no se leen en los Compostellani, pero éstos, por su parte, comparten otras muchas noticias con los Burgenses hasta la muerte de Rodrigo Díaz de Vivar en 1099 (era 1137 en ambos textos).

Todavía en el s. XII, hacia 1180, un monje probablemente de Santa María la Real de Nájera tuvo acceso a un ejemplar de los Annales martyrum codicis Rotensis e incluyó el catálogo de los perseguidores de esta obrita al comienzo de la denominada Chronica Naierensis (lib. I,1).

Al mismo tiempo, un manuscrito con la Crónica de Albelda y los anales que he denominado Annales martyrum codicis Rotensis, un ejemplar no muy diferente, sin duda, al códice de Roda, habría llegado hasta el monasterio de Santa Cruz de Coímbra, donde, hacia 1190, fue compilado el denominado Chronicon Conimbricense mixtum, en cuya elaboración parece haberse recurrido a las dos fuentes citadas. Este cronicón habría sido empleado a continuación en la elaboración de los Annales Lamecenses en Lamego en 1262.

Fecha de recepción del artículo: Octubre 2010

Fecha de aceptación y versión final: Febrero 2011

${ }^{136}$ G. MARTíneZ DíEZ, Tres anales burgaleses, p. 232. 